\title{
El jefe deviene un lector caníbal: mímesis, persona e intención entre los matsigenkas
}

Le chef devient un lecteur cannibale: mimesis, personne et intention chez les Matsigenka

The leader becomes a canibal reader: mimesis, person and intention among the Matsigenka

\section{Esteban Arias}

\section{OpenEdition}

Journals

Edición electrónica

URL: http://journals.openedition.org/bifea/7930

DOI: $10.4000 /$ bifea.7930

ISSN: 2076-5827

Editor

Institut Français d'Études Andines

Edición impresa

Fecha de publicación: 1 abril 2016

Paginación: 193-225

ISSN: 0303-7495

Referencia electrónica

Esteban Arias, «El jefe deviene un lector caníbal: mímesis, persona e intención entre los

matsigenkas », Bulletin de l'Institut français d'études andines [En línea], 45 (1) | 2016, Publicado el 08 abril 2016, consultado el 06 noviembre 2020. URL : http://journals.openedition.org/bifea/7930 ; DOI : https://doi.org/10.4000/bifea.7930 


\title{
El jefe deviene un lector caníbal: mímesis, persona e intención entre los matsigenkas
}

\author{
Esteban Arias*
}

\begin{abstract}
Resumen
Los kirineris constituyen un subgrupo matsigenka de contacto reciente. Desde las primeras noticias de su presencia han sido considerados, por matsigenkas ribereños y blancos, como los salvajes de las cabeceras en la margen derecha del Urubamba. En tal escenario regional aún de actualidad, un jefe kirineri explora e incorpora la alteridad mientras produce su propia identidad. Este ensayo examina los discursos y acciones con los que este jefe ejecuta la «facultad mimética». Son dos las entidades a las que hace frente con este propósito: el caníbal salvaje desprovisto de intencionalidad, y la intencionalidad invisible del libro. Con el fin de entender este idioma de la alteridad, un foco central de este ensayo será la teoría matsigenka de la persona.
\end{abstract}

Palabras clave: matsigenka, kirineri, Amazonía peruana, intencionalidad, mímesis, canibalismo, escritura

\section{Le chef devient un lecteur cannibale : mimesis, personne et intention chez les Matsigenka}

\section{Résumé}

Les Kirineri constituent un sous-groupe Matsigenka contacté récemment. Dès les premiers témoignages de leur présence, ils ont été considérés par les Matsigenka riverains et les blancs comme les sauvages des sources de la rive droite de l'Urubamba. Sur ce scénario régional toujours d'actualité, un chef kirineri explore et incorpore l'altérité tout en produisant sa propre identité. Cet essai examine les discours et les actions par lesquelles ce chef exerce sa « faculté mimétique ». Ce dernier se confronte

Laboratoire d'anthropologie sociale, Collège de France. 52 rue du Cardinal Lemoine, 75005 París, France. E-mail: yoesotro@gmail.com. 
à deux entités distinctes : le cannibale sauvage dépourvu d'intentionnalité, et l'invisible intentionnalité du livre. Pour parvenir à comprendre cet idiome de l'altérité, cet essai prêtera une attention spéciale à la théorie matsigenka de la personne.

Mots-clés : Matsigenka, Kirineri, Amazonie péruvienne, intentionnalité, mimesis, cannibalisme, écriture

\title{
The leader becomes a canibal reader: mimesis, person and intention among the Matsigenka
}

\begin{abstract}
The Kirineri are a recently contacted subgroup of the Matsigenka people. Since first accounts of their presence, riverine Matsigenka and white people have considered them to be the wild inhabitants of the headwaters of the Urubamba's right bank. Today, still living in this dynamic, a Kirineri chief explores and incorporates alterity while producing his own identity. This essay examines the discourses and actions by which this chief improves his "mimetic faculty". Two entities concern him: the cannibal devoid of intentionality and the invisible intentionality of writing. To understand this idiom of alterity this essay will pay special attention to Matsigenka personhood theory.
\end{abstract}

Keywords: Matsigenka, Kirineri, Peruvian Amazon, intentionality, mimesis, cannibalism, writing,

Antes de salir de Nuevo Mundo, Erenando me contaba en detalle cómo es que había presenciado una escena de canibalismo entre los kogapakoris. ¿Cuál será la gradiente de verosimilitud? Erenando parece no querer acercarse más a los bordes salvajes, acusa a los pobladores de río arriba de ser Kirineri-Kogapakori. Sin embargo afirma haber comido gallinazo, serpiente, murciélagos. Todo parece a su vez tan cerca del mito del Viaje por el Mundo. Erenando habla ahora obsesivamente de Tasorintsi, de instalarse de una vez por todas en Nuevo Mundo, de asistir al templo. Porta el día entero un excéntrico casco naranja de la compañía. Justo ahora cuando escribo aparece Erenando con su camiseta del Bayern. No sabe leer pero hace como que lee, se acerca al calendario en la pared, señala largo rato «2010» y pronuncia «suyo». Extraña homofonía. Sigue con la mirada y el dedo índice, cerca del mentón, los días del mes de julio y dice «su pelo». (Cuaderno de Campo 10/07/2010, Nueva Luz, Bajo Urubamba. Cusco)

Erenando es lo que podríamos llamar un jefe entre los matsigenkas ${ }^{1}$ de contacto reciente denominados kirineri. Rayando los sesenta años, su posición de jefe se

1 El pueblo matsigenka (arawak subandino) habita principalmente en las cuencas y los afluentes de los ríos Urubamba, Madre de Dios y Manu en las selvas tropicales del Cusco, Perú. Su población se estima hoy día en aproximadamente 15000 personas. Este trabajo asume sin ninguna pretensión jerárquica que tanto los colectivos locales kirineris como kogapakoris constituyen subgrupos del subconjunto global arawak subandino matsigenka. El subgrupo kirineri sostiene hoy relaciones esporádicas con los matsigenkas ribereños, los yines (piros) y los kogapakoris. Sus contactos con grupos de lengua pano que suelen Ilamar «chitonahua» es más bien violento. 
circunscribe a un grupo de familias asentadas hoy y desde finales de la década de 1990 en dos afluentes del río Pakiría (Kipatsiari y Mañokiari, cf. figura 1); su ascendencia sobre otro grupo de familias más al interior es fluctuante. Vivaz orador, dispone por ejemplo de un vasto repertorio de cantos matikagantsi (cantos de interacción intraespecífica) que despliega con cuidado desinterés durante las noches. En los asentamientos bajo su influencia, Erenando es el único en ejercer la

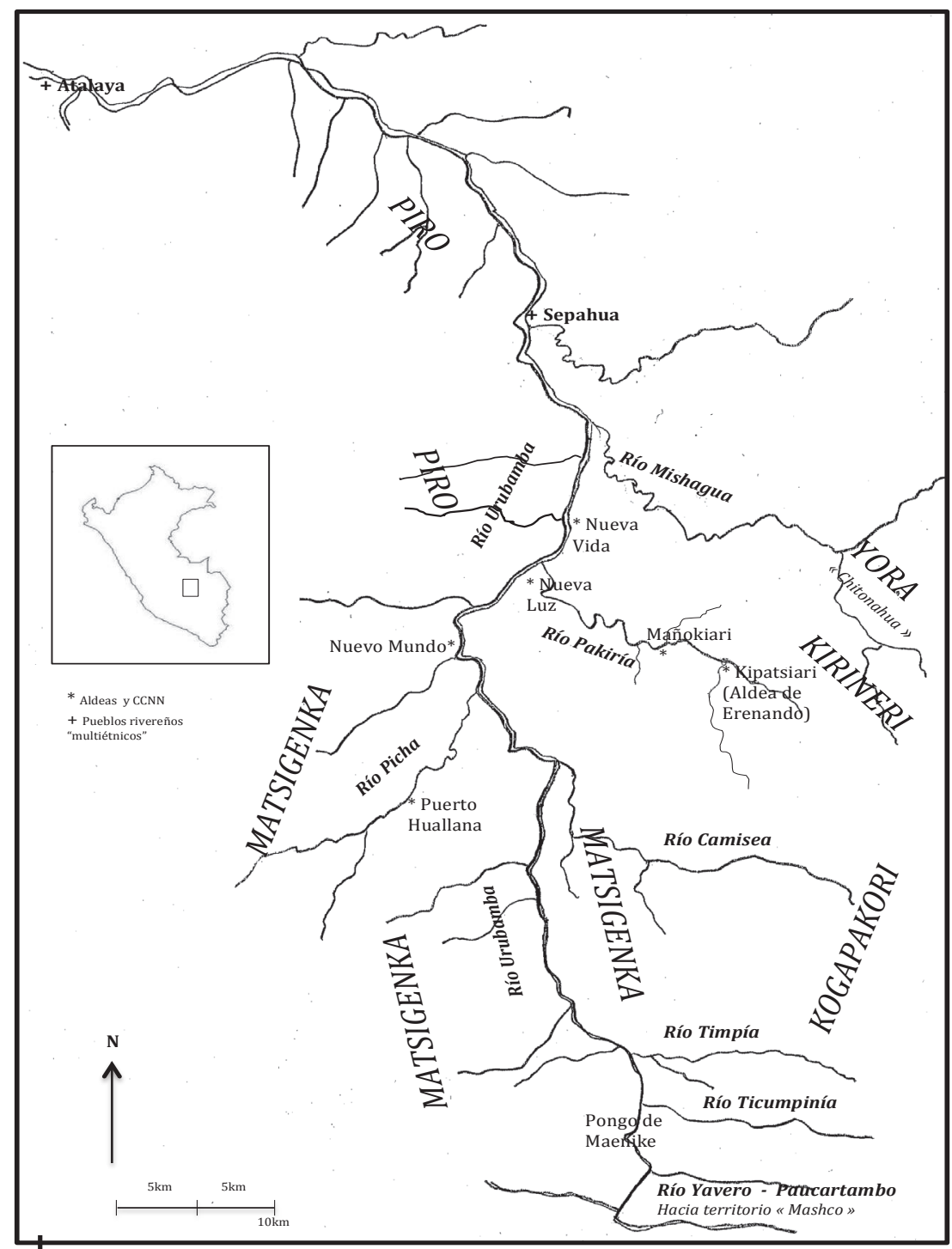

Figura 1 - Mapa del Bajo Urubamba donde se señalan algunos de los lugares, ríos y colectivos mencionados en el artículo

(c) Esteban Arias, a partir de Cartas Nacionales de la cuenca del Alto y Bajo Urubamba (Cusco) 
poligamia y destaca como un eficaz organizador de actividades colectivas tales son las pescas al barbasco. Por su frecuente movilidad en la región detenta un amplio conocimiento del imbricado sistema fluvial que pueblan los kirineri, kogapakori y chitonahua. Algunos episodios recientes le han valido mayor autoridad, por ejemplo, su emergente rol de intermediario con los matsigenkas ribereños, principalmente con la Comunidad Nativa «Nueva Luz» y últimamente con la de «Nuevo Mundo». Desde la muerte de su hermano Manuel, a finales de la década de 1990, es Erenando quien procura las alianzas matrimoniales en los grupos de los dos afluentes del Pakiría arriba citados. Durante esa década una serie de cambios sociales entra en proceso en la región poblada por los kirineris. Agentes y bienes externos no humanos (epidemias, machetes, ropa, perros de caza), así como humanos (madereros, pastores evangélicos indígenas, técnicos petroleros), confluyen en la región generando desplazamientos, fusiones y fisiones de grupos residenciales basados tradicionalmente en un sistema de integración político económica a escala de familia (Johnson, 2003: 2). Frente al mundo externo los grupos kirineris han generalmente experimentado ese proceso como una intensa serie de perturbaciones. Entre las acciones emprendidas por los kirineris se cuentan por lo general el ataque de campamentos, el robo furtivo de utensilios o el abandono de sus asentamientos. No obstante su agencia colectiva o personal es más compleja. Para entenderla propongo entonces movernos a un terreno de pertinencia (cosmo) política para los matsigenkas, el de las transformaciones. El objetivo de este ensayo es comprender los procedimientos miméticos por los que Erenando explora la alteridad en la coyuntura histórica actual de la región. Cada acción mimética de Erenando incorpora algo del otro valiéndole en el seno de su colectivo cierto grado de transformación. Así, a la luz de ciertas acciones, discursos de este jefe y contextos de enunciación, propongo vislumbrar la «facultad mimética empática» como vehículo de la capacidad colectiva kirineri de definir e intervenir en los eventos (Taussig, 1993; Santos Granero, 2007; Bubandt \& Willerslev, 2015). Abordaré el proceso mimético como un paulatino tejido de comunidades de intenciones con los que se trasciende la diferencia tanto como se reafirma la identidad. Voy a retener principalmente de la cita que abre este ensayo dos temas, el devenir antropófago y el devenir lector. Ambos temas representan emblemáticamente dos polos de la imaginación sociológica y del idioma de la alteridad matsigenka: el extremo salvaje y el civilizado, el kirineri-kogapakori y el virákocha.

Los discursos y contextos en cuestión son performativos primero porque el sujeto que los enuncia, desde su posición política, es un enunciador socialmente conminado a legitimar su rol por medio del buen uso de la palabra tradicional. Segundo, con ese buen uso consigue atribuir posiciones de sujeto específicas a entidades imaginarias. Tercero, porque es por medio de la narración de la interacción mimética con tales entidades que su realidad es habilitada. Y cuarto, porque de la existencia de tales realidades sobreviene también una redefinición del propio colectivo. Hasta aquí contamos con criterios pragmáticos para vislumbrar la construcción de «referentes» de alteridad. Para entender la totalidad del fenómeno nos es también preciso identificar en qué sustrato de la sociabilidad los matsigenkas reconocen el nexo entre interioridad y fisicalidad de una parte, 
y entre individuos y colectivos de la otra. La pista principal que nos ofrece la etnografía es la «intencionalidad», lingüísticamente representada por la raíz verbal -kog- que hace parte del término que define al salvaje: «kogapakori». Ahora bien, por la facultad mimética de Erenando «aparecen» en dos direcciones ontológicas distintas los referentes caníbal kirineri-kogapakori, y una entidad invisible de la que la escritura del virákocha (la gente blanca) es garante de la interacción2. Ambos polos de alteridad representan de un lado a una persona sin visos de intención, el antropófago, y del otro a una interioridad intencional pero sin apariencia exterior humana, el inner speech del libro. ¿Cómo abordar la verificación pública de esas entidades y las mímesis operadas? A través de las dos situaciones que Erenando explicita como contextos de la comunidad de intenciones: la de comensal y la de lector. Ambas despliegan una serie de representaciones de la noción matsigenka de persona. En el seno de las entidades animadas y susceptibles de posicionarse como sujetos, las diferenciaciones ontológicas matsigenkas se operan a partir de las representaciones de la persona. La intencionalidad, como sustrato común entre el cuerpo y el alma, el individuo y el colectivo, juega un rol central. Veremos acá que blancos y salvajes, como ejemplos particulares de intencionalidad, son objeto de representaciones cosmopolíticas históricamente complejas.

Este ensayo se compone de cuatro partes. La primera aborda las cuestiones referentes a la noción de persona en el régimen ontológico matsigenka; la segunda traza una genealogía, para la región del Urubamba, de los términos que representan al salvaje como humano provisto o desprovisto de intencionalidad; la tercera aborda el mimetismo de Erenando con el «caníbal» kirineri-kogapakori; y, finalmente la cuarta analiza su transformación en «blanco» siguiendo como hilo conductor la experiencia mental de la lectura desde el punto de vista matsigenka.

\section{TRANSFORMACIÓN, INTENCIONALIDAD Y «PERSONA» MATSIGENKA}

En matsigenka la raízverbal a la base del término que da cuenta de la «transformación» es -peg-. Por lo tanto un solo verbo (ipegaka) designa las metamorfosis operadas en los planos interespecífico (un chamán que deviene jaguar), el de la percepción o la referencia que le son correlativos (ver una gruta como una choza, escuchar un chillido como una frase verbal) y el del parentesco (un primo cruzado que deviene esposo). Lejos de banalizar la raíz verbal -peg- que podríamos considerar como el átomo de la referencia chamánica (seripegari: chamán, cf. Arias, 2015), su generalizado uso impregna de relevancia epistemológica y cosmopolítica las acciones e intenciones que involucran transformación. En este ensayo voy a referirme a la transformación desde los discursos cotidianos y míticos y respecto

2 C. Fausto denomina «canibalismo» al consumo de los componentes activos y predadores del otro, mientras que «antropofagia» al consumo de sus componentes pasivos y de presa (Fausto, 2002; 2007). En este artículo esa distinción será operada solamente hacia el final. 
al ámbito interespecífico. En ese sentido no pienso evocar la idea de una metamorfosis ontológica acabada y estable, un total devenir otro de Erenando, sino más bien el proceso de comprensión y apropiación de la diferencia en atento resguardo de la propia identidad; proceso que caracteriza a la «mímesis empática» (Bubandt \& Willerslev, 2015: 19). Estos procesos miméticos se inscriben en el escenario cosmopolítico de «apertura al otro» (Lévi-Strauss, 1991; Vilaça, 2015: 206) y son constitutivos de la producción de la vida social así como de la actualización de los saberes comunes y especializados. La disposición de Erenando a la transformación es acompasada por la «inconclusión ontológica» de la persona, cuya direccionalidad es marcada por una fuerte curiosidad epistemológica, lo que Renard-Casevitz ha caracterizado como la orientación englobante y anexionista del sistema de comprensión matsigenka (Renard-Casevitz, 1995: LXI). Como veremos, la etnografía matsigenka demuestra que el «coeficiente de alteridad» (Lima, 2005) que aplican a objetos del mundo susceptibles de devenir sujetos, abarca entidades que escapan al espectro de lo que por lo general términos como «étnico», «cultural»o «social» refieren: asociaciones humanas.

En términos generales podemos decir que los matsigenkas detectan la diferenciación ontológica en la estructura de relaciones entre la interioridad y la fisicalidad de las entidades (Descola, 2005); en términos puntuales son sus actos (mentales, verbales, físicos, sociales) los que delatan —o voluntariamente opacan - la intencionalidad. En la rebosante actividad de la selva son los actos que se orientan a la interacción los que convocan la operación de diferenciación. Es decir, acciones comunicativas, de amaestramiento u hostilidad, entre otras, son susceptibles de ser motivadas por un estado interno similar al humano. Un matsigenka, una persona, se construye en el proceso que permite un flujo regular de agency y de intencionalidad entre las escalas de lo personal, del grupo social y de la esfera exterior en que se posicionan sujetos con estructuras diferentes. Una de las modalidades matsigenkas de dación de nombre nos proporciona un buen punto de partida para entender la relevancia social de esta «alteridad constituyente» (Erikson, 1986).

El sistema onomástico matsigenka combina métodos exonímicos y endonímicos, es decir, los nombres pueden venir de fuera e individuar a un sujeto, o circular entre miembros de generaciones alternas y procurar cierta profundidad genealógica. Como ejemplo de la primera modalidad se encuentra el nombre que recibe un niño como resultado de un ataque perpetrado por entidades no humanas. «Motiogiroki» (un pequeño pájaro carpintero) y «Manearoke» (un arbusto de frutas tóxicas) son los primeros nombres de dos mujeres hoy día adultas que, cuando niñas, la primera señaló con mofa al ave provocando el ataque espiritual sobre su madre; la segunda confundió los frutos del arbusto con los de una palmera y enfermó luego. Fiebres y síntomas de dolencia gastrointestinal en el seno de una familia con neonatos o niños en edad prelingüística, son interpretados como la abducción del alma (yagasuretaka) cometida por un agente animal o vegetal. El niño puede ser víctima inocente o bien objeto de venganza por un acto irrespetuoso, generalmente la burla del comportamiento de la especie. La 
hostilidad espiritual puede recaer sobre el niño o sobre su entorno directo de sociabilidad. Este rapto del alma deja en claro que para los matsigenkas la dualidad «individuo/colectivo» pasa a un segundo plano frente a la importancia empírica de las relaciones que construyen la persona, y de las intenciones que integran desde adentro y estructuralmente al colectivo. La hostilidad se cierne sobre el isure (yagasure-taka)3, la imagen personal interior (reflexiva e intencional) que los matsigenkas consideran en progresiva construcción colectiva (Rosengren, 2015). A fin de restaurar el equilibrio, la facultad mimética empática —en clave nominal— despliega entonces la capacidad referencial y la fuerza performativa del nombre (Taussig, 1993; Von Bruck \& Bodenhorn, 2006). La eficacia del acto mimético, es decir la incorporación de parte del etograma de la especie hostil, presupone: la discontinuidad corporal sobre el fondo de la similitud de intencionalidades, así como la continuidad entre los nombres y sus referentes. La hoy adulta Motiogiroki y el pájaro Motiogiroki constituyen dos tipos de persona distintas que intersectan sus identidades. En matsigenka existen dos términos comparativos que podrían describir el «parecido» establecido entre la mujer y el pájaro: okañotaka y okantaka. El escogido por los hablantes matsigenkas para este «parecido» en particular es okantaka dado que connota en prima facie la semejanza interna y luego la externa, mientras que okañotaka apunta primero a la apariencia externa o física4. En una misma aldea todos conocen más o menos con detalle las circunstancias de mímesis como estas realizadas por otros miembros de su comunidad. Tal imitación no constituye un acto de transformación completa, pues permite al sujeto humano volver sobre su identidad procurándose una comunidad de intenciones con la especie hostil. Como un decimal periódico puro la identidad es irreductible por más ínfima e inapercibida se vuelva. Esta irreductibilidad, que los matsigenkas traducen afectivamente como la nostalgia de la convivialidad (ikenkisureaka), es un motivo regulador de las transformaciones en la mitología matsigenka (cf. Arias, 2003: 13-29).

Detengámonos un instante en el término «matsigenka». En principio «matsigenka» no es un etnónimo sino más bien una categoría que designa la posición de «persona» de una entidad animada. La categoría es usada por los kirineris, kogapakoris y matsigenkas ribereños. Con ella se señala la existencia en humanos y no humanos de un mínimo de atributos esenciales de la persona como son una consciencia autónoma reflexiva, intencional y afectiva, la capacidad de reconocimiento, un sistema de comunicación lingüístico, una morfología autónoma pero socializable, una imagen capaz de convocar afectos (como la nostalgia ikenkisureaka, cf. supra). Estos atributos se encarnan en las expresiones de diversos componentes relacionales de la persona que corresponden respectivamente a isure, ishigentiare, iriniane, ivatsa, ishinianga. La estructura de relaciones entre interioridad y

3 El i-sure es el primer componente interior de la construcción social de la persona. Y-aga-sure-taka (3pm-acto de extracción-alma-perf.).

4 Como sucede por ejemplo en la escena en que Pachakamue, el niño/adulto transforma en aves a sus primos cruzados, Pachakamue dice: «Padre, aquellos ia qué se parecen (ikantaka) esos cantantes? ¿Cómo se llaman? Aquellos parecen (ikantakenkani) Guacamayo rojo, Guacamayo amarillo, Loro (...)» (Arias, 2003: 46). 
fisicalidad acentuará o atenuará en cada tipo de entidad algunos o todos estos atributos o componentes, a veces al punto de eliminarlos del continuum. A pesar de las variaciones y la discreta aparición de algunos componentes según regiones (Baer, 1994: 76-77; Rosengren, 2004: 48; 2006b: 95), de fondo se delata como común el proceso de producción y la estructura continua de sus representaciones. El componente reflexivo, intencional y afectivo isure (que los misioneros han traducido como «alma») se halla en el polo interior del continuum de la persona y aunque puede ser percibido en circunstancias particulares, sus contornos son más bien elusivos. El isure, cuya forma verbal (isuretagantsi) designa parte de los actos mentales, cuyo sitio privilegiado es el corazón, pero que puede ser abducido por la coronilla o los ojos, se halla liado a través de una serie de posiciones — que producen los otros componentes-, a la imagen afectiva exterior, nítidamente antropomorfa y posmortem de la persona, el ishinianga. El isure constituye el molde abstracto de los demás componentes, así como es el representante metonímico de la interioridad en la narrativa mítica. Los demás componentes son objeto de discusión en circunstancias de agresión espiritual. Cada uno de ellos tiene su contexto propio de interacción, su posicionamiento con el mundo.

Por ejemplo el ishigentiare es la imagen antropomorfa que se mueve en la pupila de uno en tanto que reflejo del otro. El ishigentiare constituye una suerte de concepto sensible. El hecho de aproximarse a alguien para ver su alma, el intercambio de posiciones en abismo que implica que el otro sea la imagen antropomorfa en y de uno mismo, es muy rara vez objeto de discurso. Los matsigenkas antes de cualquier definición prefieren siempre un mismo gesto para explicar esta imagen del reconocimiento: piden acercarse a la persona y con un dedo interpuesto entre sus ojos y los nuestros, proyectando su cuerpo hacia delante y mirando fijamente una de nuestras pupilas, lo mueven en garfio provocando e imitando el movimiento. La producción de este componente no se circunscribe exclusivamente a la esfera espiritual de la alteridad constituyente, sino que es también un resultado físico de la comensalidad. El alimento matsigenka por excelencia es la yuca (sekatsi), este tubérculo constituye el epítome del trabajo familiar y la substancia vegetal base de la vida convivial en que se construye toda persona; el ishigentiare, imagen interna del reconocimiento, es el beneficiario directo de su consumo (Baer, 1994: 211). Erenando decía que el ishigentiare es el muchacho cuya casa es nuestro ojo y que bebe masato (la chicha a base de yuca) cuando nosotros bebemos masato con las visitas. Fuera de tal circunferencia doméstica, la imagen es la responsable, durante sus vagabundeos nocturnos en la selva, de los sueños de cada persona. Siendo en estas circunstancias víctima de un acto de predación podría acarrear la progresiva abducción de su molde abstracto, el isure. Uno de los agentes potencialmente hostiles de esta imagen errante, forjada del reflejo de los otros íntimos y de la colaboración productiva en las huertas y transformativas en la cocina, es Kashiri (Luna), el dios que antes de devenir antropófago y mudarse al cielo, obsequió la yuca y el arte de la horticultura a los matsigenkas (Arias, 2003). Este acto de predación espiritual, el ipugatakari que sufren los cazadores confrontados a los Dueños (cf. infra), o aquel más arriba citado a propósito de la onomástica, muestran que la cohesión del continuum es bastante frágil y a menudo el objeto de perturbaciones externas. Otro ejemplo 
es la perturbación ante la súbita aparición de una confusa imagen antropomorfa en el campo visual, o por la audición de una frase sin emisor evidente en la foresta. El estado de «repentina confusión» que provoca la representación de componentes escindidos es llamado en matsigenka ikomutagatake (Shepard, 2002: 207). El isure puede ser abducido ante la aparición de una imagen sin intención o interioridad aparente (la imagen antropomorfa o ishinianga), o la audición de una interioridad errabunda sin imagen aparente (la voz o iriniane). La imagen o la voz escindidas de un continuum o persona, suerte de «propiedades sin portador» (Merleau-Ponty, 1964: 33), provocan un efecto simétrico en el continuum del inopinado paciente.

Con respecto a la transformación en persona, en la tradición oral es frecuente la expresión imatsigenkatira. Se le asocia a los tiempos míticos pairani y se entiende por ella que tal o cual personaje mítico pasó repentinamente a actualizarse en su forma antropomorfa. Una audaz comparación matsigenka, que hace honor al «anexionismo» de su sistema de comprensión, servirá a clarificar esta súbita actualización. Una tarde, a la vista y paciencia de varios adultos, jugaba con un grupo de niños a animar figuras mediante folioscopios. Días después uno de los adultos que había gustado de la técnica, y con el que nos ocupábamos durante algunos días de la traducción de varios mitos, la utilizó en slow-motion, para ilustrarme el proceso de imatsigenkatira.

En ese tiempo —adapto su explicación—, jaguar era así: en una hoja tienes matsigenka (forma humana) y en otra jaguar y en otra invisible y luego otra vez matsigenka y otra vez jaguar y a veces invisible. Cuando imatsigenkatira tienes de pronto muchas hojas seguidas de matsigenka durante un tiempo y tal vez luego otra vez de jaguar. Cuando las pasas a mucha velocidad los ves y no los ves y de pronto ves solo matsigenka. Sin embargo en tu cuaderno falta la voz, cuando Jaguar se transforma en matsigenka habla como nosotros.

En toda una serie de mitos matsigenkas, al tiempo pairani se le figura como el período de esta transparencia entre los cuerpos y las interioridades, o entre las cosas y sus nombres (Arias, 2015: 56). Las entidades de aquel tiempo experimentaban más un «potencial de transformación» que una identidad segura (Severi, 2009: 473), y exhibían más un «principio de indeterminabilidad» que un contorno estable (Deleuze, 1985: 15), sean estos humanos, animales o vegetales. Una delgada línea cosmogónica y semiogónica dejó detrás ese estado de indeterminabilidad - y contraituitiva representación - cuando tales personajes devinieron finalmente los no humanos/referentes de hoy en día. A los matsigenkas de la era actual les es imposible probar a ciencia cierta (salvo para los raros y esquivos chamanes) cómo era posible la intercomprensión lingüística o la correspondencia física que el mito nos deja entender. Esta es una característica constitutiva de las representaciones míticas, así se organiza la naturaleza inverificable de su universo referencial, como la separación temporal que hace de los narradores de mitología aprendices de antiguos testimonios (Déléage, 2009: 75-76). De allí que los narradores introducen siempre los relatos sobre aquel período precisando que no fueron testigos de sus eventos. El morfema evidencial -tsa- (nokenkitsatake) informa a los auditores 
que el narrador está «citando» la palabra aprendida. Aquel tiempo es concebido como lejano y solo en circunstancias radicalmente especiales - como veremos más adelante- puede coincidir con el presente biográfico. La lejanía temporal es sin embargo relativa, las genealogías de mis interlocutores contaban en ocasiones en $\mathrm{G}+4$ a personajes míticos responsables de tales transformaciones (ver también Renard-Casevitz, 1999). En la experiencia de Michael y Beier su interlocutor nanti (kogapakori), Bikotoro, narra los mismos relatos de transformaciones primigenias glosando que los ancianos de quienes los escuchara fueron cuando jóvenes testigos de esos eventos.

Para él, entonces, la época mítica correspondería a las primeras décadas del siglo 20 (Michael \& Beier, 2004: 3).

Podríamos suponer que se trata de $\mathrm{G}+3$. Leamos el comienzo del relato mítico del Martín-Pescador:

1. Maika nonkenkitsatake pairani itsitíkini irashi Tsirepato / 2. Pairani imatsigyengatira ineiro tsinane (...) (Renard-Casevitz, 1991: 250)

Ahora voy a traer del recuerdo lo que he escuchado decir de los antiguos tiempos y de los ancestros del Martín-Pescador/En aquel tiempo él devino matsigenka y vio a una mujer (...)

En suma, a la manera del folioscopio, de su rápida baraja de figuras surge de pronto la forma matsigenka que coincide y ve la forma humana de una mujer (tsinane). Circunstancias como las del sueño pueden actualizar las mismas transformaciones. Erenando vino una mañana a contarme que durante la noche, en su sueño, había ascendido a visitar a la gente de la Vía Láctea. Durante los tres días que pasamos visitando Mañokiari Erenando soñó dos veces que ascendía a la Vía Láctea. A pesar que sus huéspedes tenían la piel amarilla y brillante — detalle que transparentaba el que se trataba de las estrellas que observa desde su patio en Kipatsiari-, su morfología y las acciones desempeñadas durante ese sueño corroboraban el que se trataba de «matsigenka».

Chapi nokisanitakeri Kamorintsikunirira... hehe enoku itimaigira impokiroite, ipegaka matsigenka kovoteri

Esta noche he soñado con Los vivientes de la Vía Láctea sí, arriba vive la gente estrella, se han transformado en matsigenka que brillan ${ }^{5}$.

En esta oportunidad el ipegaka matsigenka acentúa la transformación de Erenando en sujeto-estrella. Por las vías del sueño el jefe kirineri experimenta una comunidad de intenciones con la tribu de las márgenes de la Vía Láctea.

Renard-Casevitz muestra con argumentos históricos y etnográficos que la «identidad étnica» global matsigenka no es un continente acabado, y que el

5 La tradición oral y el chamanismo matsigenka consideran a las estrellas (impokiro) como un subgrupo de los saankarite (Tribu de los invisibles y puros), cuyo nombre ritual es osaariite (Los que provocan el verano). Los matsigenkas ribereños llaman a la Vía Láctea Meshiareni (Río del cambio de piel) y los kirineri, Kamorentsi que significa «Brazo cerrado de río», señalando de ese modo que el brillo de la Vía Láctea se debe a que sus aguas han sido represadas por los impokiro para realizar una pesca. Tanto matsigenkas ribereños como kirineri consideran que sumergirse en las aguas de la Vía Láctea sirve a renovar la piel (cf. Arias, 2001: 152; Baer, 1994: 143-206; Rosengren, 2004). 
movimiento de «ensanchamiento concéntrico» de unidades locales - como la de Erenando- se funda sobre el acercamiento, la asimilación consensuada o el evitamiento del otro y lo múltiple (Renard-Casevitz, 1985: 97). De nuestro ejemplo se deduce que potencialmente toda persona del colectivo, toda posición en el mundo, puede activar ese movimiento. Tal ensanchamiento procura el consenso de «un mundo construido por la biintencionalidad, al menos en su parte social (...), ya que el movimiento se alarga a todas las clases de seres humanos o no, y construye una multiintencionalidad» (Renard-Casevitz, 1999: 58). El paulatino ensanchamiento cosmopolítico es el resultado de un constante tejido de comunidades de intenciones.

Abordemos el desempeño cosmopolítico de Erenando desde el ángulo del «ensanchamiento concéntrico». Manuel, su hermano, ejercía influencia sobre el pequeño grupo residencial de la quebrada Mañokiari y empezaba a extenderla sobre un segundo grupo residencial río arriba del Kipatsiari. Tras una jornada de caza y habiendo detectado la amenaza de un Dueño de los Monos, muere víctima de ipugatakeri, otra modalidad de abducción del alma. A la muerte de alguien en la unidad familiar, es necesario abandonar temporal o definitivamente la locación. Ambos grupos abandonan así sus residencias buscando además alejarse de las inmediaciones de los dominios del Dueño de los Monos; la quebrada del infausto encuentro deja de ser llamada Intsipariari y empieza a denominarse Oshetoniroato («La quebrada del Dueño del mono maquisapa»). Cautela toponímica a fin de no volver a entrar en contacto con la hostil entidad epónima. En 2003, en esas circunstancias, matsigenkas de Nueva Luz interceden con Erenando para que, bajo su influencia, se reúnan su grupo y otros kirineris en la desembocadura del Kipatsairi. Erenando extendía en ese momento su ascendencia política al grupo residencial de Mañokiari; para ello había pactado el matrimonio de un joven kogapakori con una de las viudas de su hermano. El joven no poseía lazo de parentesco conocido en la región, así que abrió enseguida una brecha de alianzas potenciales entre dos «provincias». Erenando, por su parte, toma por esposas a las otras dos viudas. En ese mismo periodo, un reducido grupo kirineri del interior (dos ancianas y un joven) se aproxima al recientemente instalado grupo residencial de Erenando. El único hombre entre los recién llegados tenía una hermana clasificatoria (MZD) en Mañokiari. El desplazamiento del reducido grupo obedece a los cíclicos ataques de grupos de lengua pano, brotes de enfermedades respiratorias y la búsqueda de una alianza matrimonial. Erenando integra al hombre de ese grupo cediéndole una de sus esposas. Ahora bien, habiendo entramado de esta forma «una colectividad agregativa» más vasta (Rosengren, 2000: 224) y proyectado entonces su influencia a otros grupos residenciales, atrae a su aldea cerca de cinco familias de otra cuenca, tal había pactado con los comuneros de Nueva Luz. La aventura política no tarda en fracasar. Por su deseo de obtener nuevas esposas las familias se escinden rápidamente de su creciente autoridad6. En el desenlace se cuentan

6 Hasta donde he podido indagar la mitología del subgrupo kirineri no alberga la figura del emperador Korakonani, quien reinaba como «Kuraka» sobre miles de hombres quechua «porque tenía la 
hoy día mutuas acusaciones de brujería. Estos vaivenes del ejercicio político de Erenando son conocidos en otras regiones de la etnografía matsigenka (Johnson, 2003; Renard-Casevitz, 1985; Rosengren, 1987). El emergente escenario del contacto da pruebas de procurarle un progresivo reforzamiento de su autoridad. En tales circunstancias, la relación de poder que lo lía - o escinde- de su fluctuante grupo residencial da muestras de proceder según una difundida modalidad de «intencionalidad sociológica» en las tierras bajas: promover una tonalidad política en fragilidad permanente (Clastres, 1974: 34, 39).

En el ámbito del modelo de persona extensivo a entidades no humanas dos nociones importantes serán puestas entonces de relieve: la intencionalidad y la «intencionalidad compartida» o colectiva (Tomasello, 2014). Por intención o «sistema intencional»(Dennett, 1987) podemos primero entender, ciñéndonos al diccionario de la Real Academia Española: Determinación de la voluntad en orden a un fin. Tal definición de «intención» corresponde a lo que Duranti considera su sentido puntual (2006: 34), así como de manera general al campo semántico de la raíz matsigenka -kog-. El modelo de persona que he esbozado nos exige considerar la noción de intención también en su sentido amplio, trazable en los actos físicos como el latín tardío intentio significa. Husserl definía esta noción como la peculiaridad que las experiencias tienen de ser acerca de algo. La intencionalidad es el aboutness de la experiencia y de la acción (Duranti, 2015: 26), lo que los matsigenkas detectan como la voluntaria formación de un mismo mundo —evitándose, asimilándose o acercándose - tejido inevitablemente de múltiples comunidades de intenciones. Como lo veíamos respecto a la imagen ocular ishigentiare y la yuca, ese sentido amplio guarda coherencia con la producción de la corporalidad e interioridad en el seno de la vida colectiva. Las expresiones verbales y físicas de cólera por ejemplo son consideradas entre las más disruptivas en el ethos matsigenka. Desde la edad prelingüística los niños son regular sino diariamente bañados en abluciones calientes de plantas aromáticas y sedativas. Dos propósitos hacen concierto en estos baños, el primero es proveer al niño de un aura odorante contra entidades como las arriba señaladas a propósito de la onomástica (Shepard, 1999: 236); y el segundo es amaestrar los impulsos violentos, desprovistos de motivo, que los niños expresan ocasionalmente. Encausar al niño en la vida social requiere de un sofisticado tratamiento corporal que invoca sentidos y afectos a fin de sintonizar gradualmente sus intenciones con los del colectivo (Vilaça, 2005: 449, Surrallés, 2003: 49; Rosengren, 2015: 80). No es en vano que el trickster Pachakamue que actúa sin motivo alguno (kogapage), sea también Ilamado Kashivokani, que quiere decir «el que crece a voluntad»;

facultad de seducir a las mujeres, centenares de ellas y para retenerlas a su lado» (Renard-Casevitz, 1991: 177-178). La vacancia mítica de este antípoda de jefe matsigenka entre los kirineris se explica por circunstancias históricas concretas: lejanía de la frontera inca y aislamiento respecto a los circuitos de poder con veleidosas figuras extranjeras de jefe. El caso de Erenando muestra sin embargo que en circunstancias de «recalentamiento» histórico las alternativas estructurales locales, así como las presiones y fuerzas ejercidas de fuera, pueden propiciar la emergencia de intenciones autoritarias desmedidas. 
pues si ciertas figuras míticas son representadas como la transparencia entre la figura humana y la de alguna especie, el extraordinario y peligroso Pachakamue (cf. nota 4) en cambio es un niño aprendiendo a hablar y un chamán adulto al mismo tiempo; un niño-adulto que «sin razón alguna» transforma a sus primos cruzados en animales (Johnson, 2003: 97). Las abluciones así como la onomástica, forman parte de una serie de prácticas y procesos destinados a propiciar comunidad de intenciones en lo pasible interno del socius, como en el riesgoso mundo tras las márgenes ontológicas.

En matsigenka el campo semántico de «intención»se encuentra distribuido en una serie de términos que describen diversos actos mentales y físicos (inintaige — gustaría hacer-, yogavintsataka — querer comer-, etc.). Todos constituyen por su aparición o ausencia índices del grado de alteridad en el vasto continente de lo no humano. Es con estos índices que se detecta la interioridad intencional isure. Ella puede revestir la forma de 1) una cualidad individualizada y peculiar como en el caso de cada matsigenka; 2) individualizada en los representantes de una «especie» pero dirigida con severidad por una jerarquía de Dueños como el Oshetoniro antes evocado; 3) ampliamente distribuida como entre las plantas de una o varias especies y dirigida generalmente por un gran árbol7. Una partícula lingüística es la que consolida el puente entre la teoría de la acción y la teoría del espíritu matsigenka: la raíz -kog-. A su forma verbal transitiva (ikogakero) le corresponden los significados: buscar, querer, necesitar. Como señala A. Johnson de su experiencia en el Alto Urubamba, en expresiones que usan esta raíz los matsigenkas denotan la cualidad de willful self en entidades como animales, plantas o espíritus (Johnson, 2003: 123-124). Humanos y no humanos dan forma al mundo mediante sus acciones y decisiones. Ahora bien, es también de esa raíz que se forma el sustantivo kogapakori (el extremo salvaje) y el adverbio a su base, kogapage. Este último puede referir dos cosas: que el sujeto de la acción actúa sin razón, sin propósito o motivaciones; o bien que el hablante que evalúa el acto es incapaz de encontrarle motivo. La ambivalencia de kogapage (sin intención/ opacidad) que concierne tanto una cualidad de ciertas entidades como una (in) capacidad matsigenka, es constitutiva de esta suerte de relaciones, y causa de la fascinación que ejercen las acciones de tricksters como el dios Pachakamue, de los violentos espíritus auxiliares kogapakoriite y, por supuesto, de los humanos salvajes con los que Erenando toma contacto.

7 Esta distinción tiene lugar a nivel etnosintáctico. Por ejemplo «Tiene vida» respecto de una planta se dice ayțiora aniane y de un animal ayñora îriniane. Las partículas que subrayo ofrecen dos contrastes $t / \tilde{n}$ (vivo/no vivo), a/i (posesión distribuida/posesión singularizada), de lo que resulta para las plantas la posesión de una propiedad vital e interior distribuida o múltiple, así como en los animales singularizada. Como se ha visto iriniane es un componente relacional directamente asociado al lenguaje sonoro; más adelante veremos también que es por su condición «relacional» y fono-auditiva que sirve de índice de interioridad. 


\section{LOS KIRINERI COMO SALVAJES EN LA HISTORIA DEL URUBAMBA}

La literatura antropológica en torno a los kirineris es aún incipiente. En la actualidad se cuenta básicamente con la información que aportan los trabajos de Swierk. En la cuenca del río Pakiría se conocen al menos cinco grupos residenciales estables, pero se ignora el número y características exactas de los que se distribuyen en cuencas aledañas (fig. 1). La estimación de Swierk calcula la población actual kirineri en cien personas (Swierk, 2006). Uso el exónimo «kirineri» para referirme a un colectivo de contacto reciente que comparte lengua, rasgos socioculturales y al menos parte del territorio con los matsigenkas del río Urubamba y algunos de sus afluentes; tal es también el caso del colectivo hasta no hace mucho denominado kogapakori, hoy referido como nanti y con el que como se ha señalado más arriba, el jefe kirineri Erenando ha establecido contacto a partir de los años 1990.

El exónimo «kirineri» no encuentra aún sosiego en documento alguno pero es de uso extensivo entre los matsigenkas ribereños. A nivel regional y dentro de los márgenes de la intercomprensión lingüística, los grupos denominados ya sea kirineri o pakirianos optan de manera práctica por designarse en función del curso de agua próximo al lugar de residencia. Es por ello que Swierk ha decidido denominar al subgrupo entero «Paquirianos», que provendría del matsigenka Pakiriakunirira (lit. «Vivientes del Pakiría»). No obstante tal denominación correspondería a lo sumo a los dos grupos residenciales directamente conectados a este curso mayor de agua, ambos estrechamente vinculados a Erenando. La movilidad actual de los otros grupos entre más de una cuenca distinta del Pakiría justifica el deslinde nominal respecto a este solo eje fluvial.

El material historiográfico es escueto en cuanto a los kirineri. Sin embargo algo que es de remarcar, desde la primera mención, es el que se les señala como grupos refractarios al contacto. Ambos, kirineri y kogapakori, comparten la misma posición desde su aparición en la literatura a comienzos del siglo XIX, se les sitúa al interior de la margen derecha del río Urubamba y son ampliamente temidos por piros y matsigenkas. Esta posición la comparten casi de pleno con otro colectivo de «salvajes», los mashco, como se denominaba a diversos grupos de la familia lingüística harakmbut desde el siglo XIX.

Una progresiva sintonía de miradas, indígenas y virákocha (el blanco), hacia el interior de la margen derecha del Urubamba, va adjudicándole consistencia histórica, es decir, contra el «progreso», a la figura del indio salvaje que desde su mención en 1806 encarnan los guirineri, cocapacori y mashco. Esa primera mención se la debemos al padre Fray Ramón Busquets, quien descendiendo el Urubamba, en las inmediaciones del Pongo de Maenike, es informado de la presencia de «Cocapacoris» en las alturas del Ticumpinía8. Cerca de dos semanas después, el 15 de septiembre se halla en la desembocadura de lo que hoy

8 Ciento treinta y nueve años más tarde, en este mismo río, el patrón local Angulo es asesinado por matsigenkas «civilizados» y kogapakori luego de haber cometido correrías contra estos últimos (Ferrero, 1947). 
conocemos como el río Camisea, habitado tres días arriba por los «Guirineri»9. Casi cuarenta años después, en 1845, la expedición de Castelnau y Marcoy, en la que fallece el ya octogenario Fray R. Busquets, da cuenta una vez más de los «pucapacuris». Mediante el artilugio de la voz indirecta, es un «anti» (matsigenka) quien esta vez describe el río Camisea y ubica en él, a ambos lados, a la tribu «pucapacuris» aliada con los impetiniris, los tuyneris, huachipayris y siriniris, es decir los mashco. Hablan todos la misma lengua y están en «guerra abierta»con los matsigenkas y piros. Un fino grabado del célebre artista É. Riou nos da cuenta esta vez del identikit del temible y desnudo pucapacuri. Otra alusión retiene la atención luego, y es que respecto al temor que inspiran los pucapacuris, ni matsigenkas ni piros suelen frecuentar los ríos «Pacria» y «Misagua» (fig. 1) en la margen derecha del Urubamba (Marcoy, 1869).

La introducción de la navegación a vapor (1852), la desagregación geopolítica de la Provincia de La Convención (1857), la exploración científica programada por La Comisión Hidrográfica del Amazonas (1867), los intentos de evangelizar e integrar económicamente a la población indígena del Urubamba, así como de establecer una línea ferroviaria de penetración como parte del plan de la Junta de Mainike (1869)10 alcanzarán mayormente éxito o renombre en las regiones del Alto Urubamba y preferiblemente — de no ser por valles aledaños enteramente matsigenka-, en su margen izquierda. Esas empresas de evangelización e integración económica solo concebían posible su actividad sobre una diferenciación operada entre matsigenka y piro, «inclinados a la civilización», y los kirineri, kogapakori y mashcos, «los más alevosos y asesinos»11. Esta última es frase de Raymundo Estrella, quien durante uno de sus viajes de exploración del Urubamba hacia Iquitos, en 1871, debía hacer repertorio de las tribus y características hidrográficas de la región. El fin era facilitar la empresa de pacificación y disposición económica ordenada por La Junta de Mainike (Sala, 1998: 438, 451). En el Camisea se señala entonces, nuevamente, la presencia de «Mashcus» o «Puca pacuris» y más arriba, sobre el Urubamba, a los «lpetineri». Los términos kirineri, kogapakori, mashco y el hoy en desuso impetineri, es evidente, participaban de una típica transitividad referencial forjada en la discontinuidad entre aquellos indios tratables por las vías de la asimilación religiosa y económica (matsigenka y piro), y los otros, salvajes intratables, condenados a la punición militar o al azote de las enfermedades.

9 A. Gray se inclinó por pensar que «presumiblemente» esta designación refería al grupo Sirineri, perteneciente a la familia lingüística Harakmbut (Gray, 2002: 42).

10 El Pongo de Maenike (Maenikü) es el fastuoso cuello de botella que divide las regiones del Alto y Bajo Urubamba en el teritorio matsigenka. Para los matsigenkas es un topograma sagrado estructurado por varias edificaciones responsabilidad de antiguos chamanes. Hasta el día de hoy es un lugar de peregrinación alucinatoria en las iniciaciones chamánicas. Difícil garganta de río, ha desde siempre constituido un mal paso para toda empresa colonizadora (cf. fig. 1).

11 Es cierto que como Gow anota (1991: 34) otra clasificación más bien «religiosa» se intersecta a la aquí propuesta. Esta establecía una diferenciación a tres rangos, indios cristianos, infieles y salvajes. Eran los infieles los que practicaban correrías sobre los salvajes. La clasificación simple que procede de mi suscinto análisis no contradice la «religiosa», sino que proviene de observar el tablero desde el punto de vista de la administración regional y republicana. 
La debacle demográfica y la secuela de desestructuración sociopolítica en numerosos grupos de la margen derecha, desencadenará la progresiva identificación —a veces ya en ausencia - de los colectivos denominados mashco. Este proceso se extiende desde el inicio de las expoliaciones y abusos de los barones del caucho y sus secuaces indígenas, hasta la década de 1940, era de la fundación de las misiones estables de los dominicos en las regiones de Madre de Dios y Urubamba. 1940 es también fecha de la muerte del carismático patrón esclavista del Ucayali, Pancho Vargas, pivote local de la «interpenetración» de elementos indígenas y extranjeros (Gow, 1991: 68). Tres años luego la carretera Lima-Pucallpa es inaugurada; con ella la explotación de la madera en el Bajo Urubamba se intensifica junto con las relaciones asimétricas entre patrones, indígenas madereros y «salvajes». El dominico A. Ferrero encuentra instalado en 1947 al curaca Shironkama en la boca del Camisea. El curaca matsigenka Shironkama y su secuaz Shopiro, conducían correrías al servicio de los patrones Collazos, que en época del caucho había creado la gobernación del Bajo Urubamba (Sala, 1998: 486), Bazagoitia instalado en su célebre campamento No me olvides y Pepe Pérez, conocido como Peirishi por los matsigenkas, e hijo de Jaime Pérez, patrón en el Madre de Dios durante el boom del caucho. Todos negociaban los esclavos así obtenidos en los puestos de Sepahua y Atalaya con destino a las haciendas del río Ucayali, a Iquitos y otras ciudades. Ferrero observa que río arriba del puesto de Shironkama, en el Camisea, se encuentran los Karinieri (Ferrero, 1947), tal como en 1806 anotara Busquets. En su libro Los Machiguenga, el mismo dominico, retomando aquel viaje de 1947 añade que en la ocasión sus guías matsigenkas le aconsejaron de no pernoctar del lado derecho del río, pues podrían ser atacados por kugapakuri, a los que el padre identifica todavía con los «masco» y que, según él, serían los mismos que habitan el Alto Timpía. Sus guías añaden que una característica física es que son «barbudos» (Ferrero, 1967: 394). Es en el curso de estos años que la región empieza una serie de transformaciones conducentes a la creación de lo que décadas más tarde serían las Comunidades Nativas. Es también la fecha de la llegada de un nuevo e importante actor local, la misión evangélica del Instituto Lingüístico de Verano (Davis, 2002; Gow, 1991; 1996; 2001). Un giro importante habría de operarse desde ese momento en la configuración geopolítica de la región. La educación asume un estatus sin precedentes y la lectoescritura se convierte en la inversión ideológica más atesorada (Franchetto, 2008).

En la comunidad de Puerto Huallana, sobre el río Picha, escuché las historias de ataques de viejos curacas sobre poblaciones kogapakori. El blanco de buena parte de los ataques eran grupos de los que se considera hoy kirineri, que habitan en el microsistema fluvial del Pakiría. Shironkama, el curaca que Ferrero hallara en el Camisea en 1947, y su secuaz Shopiro, habitaron la última parte de su vida en Puerto Huallana, a poco más de cuarenta kilómetros de donde cometían sus exacciones y asesinatos. La familia que me adoptó en aquella comunidad llevaba de ambos lados la marca de la turbulenta etapa de transición de los años 1940 y 1950 . Shironkama, dadas las circunstancias del parentesco simbólico que me acogía, venía a constituir mi abuelo paterno. Mi abuela materna en cambio 
era «kogapakori»12. Esta abuela, Shintyoveni, y su hermana Tsetsero, habían sido raptadas aún púberes en una de las correrías que se practicaran en esos años sobre una casa comunal kogapakori.

El padre de Erenando, Pasaromonki, logró escapar en el comienzo de los años 1940 a las correrías del curaca Shironkama y se instaló luego en el sistema fluvial del Camisea. Erenando mismo sobrevivió a uno de los ataques de Shironkama en el río Shiateni cuando niño. De acuerdo a los datos de Swierk (2003), Shanigori, posiblemente en los años 1950, desató una disputa entre unidades residenciales en la que dio muerte a varios otros kirineri y raptó una niña que sería más tarde una de las esposas de su nieto, Erenando. Es a partir de fines de los años 1960 que se inician una serie progresiva de dramáticos contactos con los matsigenkas de la Comunidad Nativa de Nueva Luz. Poco a poco, ante la paulatina incursión de madereros piros, matsigenkas y mestizos en la región habitada por los kirineri, los contactos reportan el ataque de hombres «barbudos» que hablan un dialecto matsigenka (Beier \& Michael, 1998; Swierk, 2006). Es en estas circunstancias que una serie intrincada de desplazamientos se inicia y Erenando, junto a uno de sus hermanos, se instala en Nueva Luz y luego en Nueva Vida, donde funcionaban ya las escuelas a las que Erenando asiste intermitentemente. Erenando solo regresará en 1982 tras un periplo que incluye Sepahua, Atalaya, Bolognesi y otros pueblos que hacen parte del archipiélago de «civilización» de la región. Erenando se instala finalmente en Kipatsiari y su hermano en Mañokiari en 1998. Ese mismo año en una reunión con una empresa petrolera, el exónimo kirineri es por primera vez pronunciado oficialmente por un líder matsigenka. Un año antes, un pastor evangélico matsigenka, hijo del chamán de Puerto Huallana, reemplaza oficialmente el término kogapakori por el de nanti.

En síntesis, el uso del referente kirineri-kogapakori en tanto que «caníbales» por parte de Erenando, lleva al paroxismo la representación regional históricamente tejida del salvaje. Morador de las cabeceras de la margen derecha del Urubamba, este feroz referente se construye en la confluencia de varias «confusiones». La confusión «fonética»: es frecuente observar reinterpretaciones fonéticamente inspiradas como la que un informante matsigenka podría haber proyectado sobre sirineri, que era ya el modo que tenían los Arasaeri de denominar a los Sapiteri (Gray, 2002: 39). Lo que nos dicen en la actualidad los matsigenkas del Picha es que kirineri procede del sustantivo küri, es decir la palmera regionalmente conocida como pijuayo (Bactris gasipaes) y remarcable entre otras cosas por el erizado pelambre — o barba - de su tronco (en piro kiruneru significa «persona pijuayo» en referencia a los matsigenkas, cf. Gow, 2011: 19). Los sufijos -eri en harakmbut (locativo) y -ri en matsigenka (nominalizador) cumplen funciones —en los términos citados - distintas, pero que se ven neutralizadas bajo el efecto de la

12 Los matsigenkas de Puerto Huallana consideran kogapakori a estas mujeres que muy posiblemente provienen de un colectivo kirineri, así como consideran a un tal Güirigüiri jefe de los kirineri (cf. nota 14). Los informantes nanti (kogapakori) de Cabeceras Aid Project, sitúan a este último como uno de sus antiguos líderes, de cuyos ataques, perpetrados en la década de 1960, procede la escisión entre los grupos de Camisea y Timpía (Michael \& Beier, 2004: 6-7). 
semejanza fonética en regiones donde el uso cruzado de lenguas completamente distintas ha sido moneda corriente.

La confusión «semántica»: lo que ha devenido por antonomasia «colectivo de asesinos» en matsigenka, es designado por el término kogapakori es decir, en términos de la definición puntual de intención arriba apuntada (cf. supra): el que no posee intencionalidad o de quien soy incapaz de detectar intenciones. El exónimo es atribuido por los matsigenkas a todo colectivo del que la violencia es un rasgo destacando siempre sobre el fondo de una completa opacidad moral. Lo que veíamos más arriba, que el explorador R. Estrella consideraba «alevosía» (es decir la cautela de esconder las intenciones de cometer un crimen), los matsigenkas lo describen como kogapage, un acto sin origen intencional como el de los trickster o niños en edad prelingüística. Cuando el acto del asesinato o más allá de él, de antropofagia, es caracterizado como un fenómeno «social» y no un acto aislado, los matsigenkas atribuyen entonces a quienes lo cometen el grado de alteridad que recubre el término kogapakori.

La expedición de Bernard Lelong proporciona un ejemplo de la actividad de estas «confusiones» y de la subyacente comunidad de intenciones. Los guías de la expedición por el Shinkibeni («Río del maíz» en matsigenka) en el Alto Madre de Dios, eran mashco «civilizados» y temían a las tribus «desconocidas» más allá de las cabeceras. Esa y la trágica expedición que le antecede en 1970 entabla contacto con gente de lengua matsigenka «pero mucho más primitivos», que llaman a todas luces por sugerencia de los guías mashco y como resultado de las dos «Confusiones»: «Huakiri» (Lelong, 1974: 214). En una de las lenguas «mashco», el Amarakaeri, «huakieri» es un sustantivo que significa «persona que reconoce» (Tripp, 1995: 117). Desde la perspectiva mashco los primitivos kogapakori han franqueado la distancia, su acercamiento (cf. supra) implica un reconocimiento y una voluntad de estructurar comunidad de intenciones.

\section{EL CANÍBAL DE ADENTRO}

Como hemos visto, en el seno de la tradición oral matsigenka los relatos se dividen en dos grupos claramente distinguibles según la relación del narrador con la fuente de la información. Partiendo del punto de vista «temático» o «cosmológico» es cierto que como dice Lévi-Strauss y subraya Viveiros de Castro, un indígena podría definir el mito como «un relato de cuando los hombres y los animales no se distinguían» (Lévi-Strauss \& Eribon, 1988: 193; Viveiros de Castro, 2009: 32). Sin embargo los matsigenkas estarían también de acuerdo en precisar que se trata de un relato de eventos que no hemos presenciado. En contraste al uso evidencial del morfema -tsa- para eventos no presenciados, los matsigenkas pueden usar la fórmula nokenkiagakeri cuando se trata de eventos de los que el narrador fue testigo; o bien, como en el caso de Erenando, pueden omitir cualquier fórmula que contiene un evidencial para deslizarse directamente en la armadura del mito desde la primera persona. 
Los grupos aislados de las cabeceras del Pakiría existen, sin embargo es un uso «decitativo» 13 de un mito matsigenka el que les procura la cualidad de antropófagos. Erenando hace un uso personal u ostensivo de un importante relato mítico, de manera tal que reivindica suyas las experiencias que el mito atribuye a los ancestros (Déléage, 2009: 45). En el mito matsigenka del Viaje por el Mundo (Renard-Casevitz, 1991: 16-22) anónimos protagonistas, exploradores de su territorio, se adentran en la selva y observan las costumbres alimenticias de diversos grupos humanos de más en más aberrantes, como de más en más lejanos en el mundo. Según una u otra versión las presas de los grupos extranjeros pueden variar, sin embargo es común a todas el que el in crescendo de la tensión ontológica, etapa tras etapa del viaje, sea signado por la bestialidad de los platillos y el desconcertante desacuerdo en torno a ellos. Conforme se entra en el territorio la alteridad se acrecienta. En una versión que registré en el Picha el viaje comienza con el encuentro de quien bebe masato en el que flotan insectos, un masato que, contra la regla, es de fabricación masculina. Las etapas de esta misma versión culminan con el encuentro de quienes dicen comer tapires cuando a los ojos de los visitantes comen segamae, el demonio lanudo dotado de enormes testículos como los racimos de la palmera sega (Oenocarpus bataua). La versión trabajada por Renard-Casevitz empieza con los comedores de serpientes que dicen comer peces, y culmina con los comedores de aves carroñeras que aseguran degustar la deliciosa pava de monte. A continuación presento las etapas de las dos versiones míticas y del relato de Erenando:

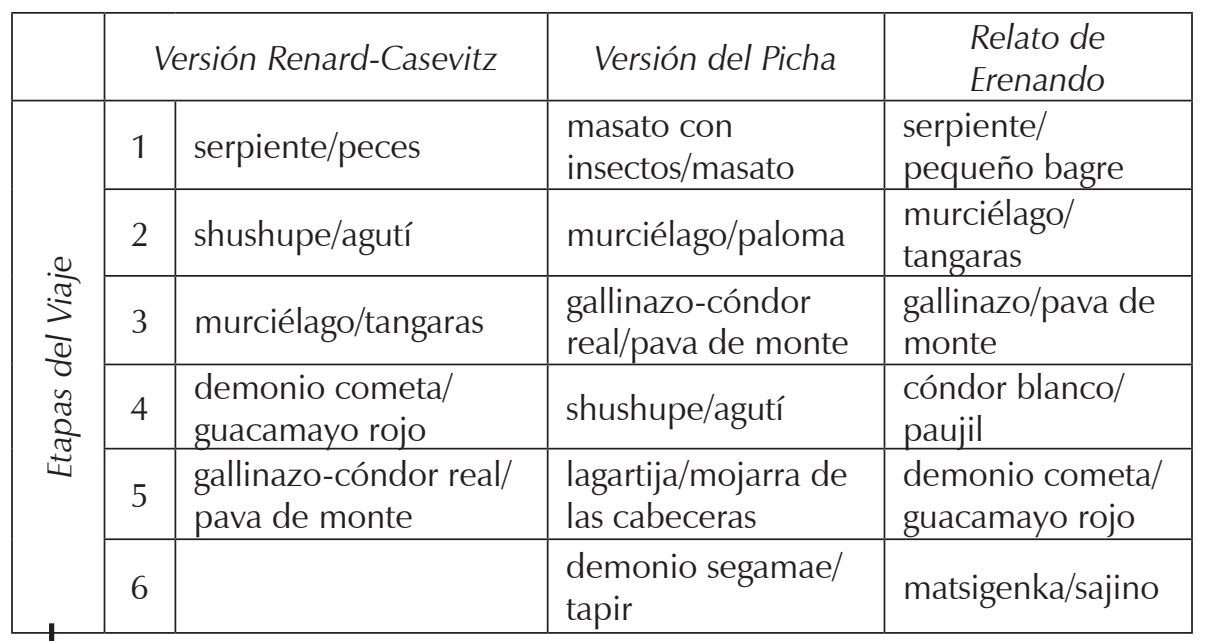

Figura 2 - Versiones mítica y decitación del Viaje por el Mundo

(C) Esteban Arias

13 Se trata del proceso de «de-quotation» (Urban, 1989). Pierre Déléage (2009) ofrece una categorización triple del acto mental de decitación. La de Erenando corresponde a la decitación de segundo grado: el préstamo de elementos de un mito que relata eventos vividos por los ancestros; «(...) la déférence inamovible vers l'ostension» (Déléage, 2009: 80). 
Erenando comenta que si los kirineri-kogapakori bajasen al Urubamba llamarían «matsigenka» a los sajinos que verían allí comer; que los caníbales llamaban «tapir» al jaguar y cuando Erenando los conminaba a distinguir su piel manchada (sankenari), los salvajes respondían «son las manchas típicas de los jóvenes tapires». La incontestable similitud de armadura y temática entre las versiones conocidas y el relato de Erenando revela el uso del acto mental de decitación. Con este acto Erenando confronta a su público a la existencia del auténtico salvaje en las cabeceras de la margen derecha del Urubamba.

Erenando pronuncia el «mito» a la manera de comentarios autobiográficos. En el contexto histórico y bajo su forma decitada, los comentarios hacen las veces de una «historia personal ejemplar» (Gow, 2014). Su especificidad sin embargo reside en la particular manera de constituir de Erenando un «fluent self» (Course \& Oakdale, 2014). En eco a la historia regional, hay un vector de profundidad hidrográfica que es transversal al mito y a su forma decitada: el narrador/personaje sufre una progresiva transformación en «salvaje» conforme remonta el río y se adentra en la selva y las costumbres de sus moradores. Este vector constituye un elemento deíctico de la alteridad matsigenka. La versión trabajada por RenardCasevitz (originalmente recopilada por el ILV) no cuenta con información sobre el narrador ni el espacio concreto del desplazamiento. La del Picha la recopilé en 2001 del hijo de Shironkama (cf. supra.) con una mujer asháninka. El vector de profundidad de esa versión discurre más bien en el río Tambo (territorio asháninka), allí los salvajes profundos son asháninka.

El encuentro de Erenando con los kirineri-kogapakori se sitúa después de su vuelta del archipiélago regional de «civilización», a comienzos de la década de los años 1990. En consideración de las fechas, supongo que el móvil subyacente del contacto era el de conseguir una esposa luego de la muerte de la que le fuera entregada por su abuelo Shanigori (cf. supra). Erenando remarca sin embargo que su intención al contactar a los kirineri-kogapakori era la de conocer y «civilizar». La primera tentativa de contacto desencadenó una respuesta violenta. Habiendo remontado el curso de la quebrada Kairoato halló signos de presencia humana. Siguiendo las reglas de la diplomacia el visitante se presentó desde las márgenes del patio «de una gruta» y sin armas a la vista. Evocó reiteradas veces sus intenciones pacíficas. Una flecha terminó hiriéndole el muslo. Escapó ocultándose en un túnel de armadillo gigante, se arrastró hacia un pequeño curso de agua en el que bebió agua ferruginosa a fin de cicatrizar la herida. Erenando guarda del episodio la elocuente cicatriz. Días después halló otro grupo matsigenka donde fue curado con pocharivenki; ahí le confirman que sus atacantes son frecuentemente violentos. En ninguna de las versiones míticas el desenlace es el canibalismo. Como lo muestra Renard-Casevitz tal resultado es el producto, en otros relatos, de múltiples transformaciones estructurales del léxico y temática del Viaje por el Mundo (Renard-Casevitz, 1991). En una nueva tentativa Erenando consigue entablar contacto mediante el ofrecimiento de un par de machetes; es entonces que empieza el uso decitativo. Durante lo que considera dos estaciones secas recorre las aldeas de sus vecinos al interior de la región, en el claroscuro de 
los territorios kirineris y kogapakoris. Les va enseñando a construir «verdaderas» casas. Cito un extracto de la primera etapa del relato:

Yogari iriroriegi iatanake inkenishiku, paita ipigaiganaa yamanakeri pigiri, ikanti 'Nero tsimeri; pigiri ipegakari tsimeri.

Ahora, aquellos [los kirineri-kogapakori] partieron a la selva de caza, más tarde volvieron trayendo consigo murciélago, y [me] dice: «Ten, pajarillos [comestibles]'; los murciélagos son tangaras [para ellos]».

En seguida Erenando narra que al final de su estadía sus huéspedes organizaron una partida de caza:

Okutagitetanae ario nokemakotiri irirori yatanake ishintoriatakera inkenishiku. Okuta yamagantiretakeri matsigenka, tera iriro shintori, piteni surari... mavani tsinane; kovenga. Nosuretake iriroegi matsonsori, itimaera imperita maikari isekataka matsigenka iriroegi ipegaka ishintorite matsigenka.

Llegado el amanecer, así fue que escuché que ellos se iban a cazar sus sajinos en el monte. Pasado un día trajeron muertos y enteros a unos matsigenka, no eran sajinos, dos hombres y tres mujeres; fue espantoso. Pensé entonces que ellos eran jaguares, vivían en grutas, ahora comen matsigenka, para ellos los matsigenkas son sajinos.

En el último enunciado el verbo transitivo ipegaka aparece para señalar el segundo aspecto de transformación más arriba reseñado, el de la percepción o referencia: ver un cuerpo humano como el de un sajino. En este evento perspectivista o de «visiones en desencuentro» (Renard-Casevitz, 1991: 25-26), un mismo acto referencial se bifurca sobre dos objetos. Dos estructuras de persona distintas se aproximan representacionalmente (signo «sajino») para designar, bajo el mismo nombre y a riesgo (fregiano), dos objetos distintos (el «cuerpo sajino» y el «cuerpo humano»; Arias, 2015: 56). Erenando se encuentra en una posición de completo desencuentro con sus huéspedes. Lejos de tratarse de una argucia solamente decitativa y exclusiva a este jefe, el motivo aparece también en el idioma de la alteridad de los nantis (kogapakori) con los que Lev Michael ha trabajado. En su ensayo sobre la ética evidencial de ese colectivo, el autor anota:

(...) murderers are talked about by Nantis as considering other people to be game animals, with murderers being identified with cannibals ${ }^{14}$.

Si asesinos y caníbales comparten el mismo halo semántico entre subgrupos matsigenkas, y si además el desacuerdo de perspectivas es siempre puesto de

14 Michael añade (cf. nota 12) que la última vez que estos asesinos/caníbales que toman por presas a otras personas aparecieron, fue en la década de 1960, liderados por Güirigüiri (Michael, 2015: 127). En el entrecruzamiento de mito e historia entre provincias matsigenkas, los matsigenkas del Picha consideran a Güirigüiri el antiguo líder «con cola» de los kirineris. Bien sea la barba «subcultural»o la cola «extranatural», los líderes kirineris como Erenando son recurrentemente representados en las márgenes ontológicas humanas. Con esos detalles morfológicos de más, los matsigenkas connotan la proximidad de los líderes kirineris con los Dueños como el Oshetoniro (cf. supra) que detentan o administran la «interioridad intencional» isure de las manadas. 
relieve, a la base se encuentra un mismo uso conceptual del adverbio intencional kogapage.

Ahora bien ¿Qué función cumple este transformarse en extremo salvaje mediante la decitación kirineri? Se puede interpretar tal acto de lenguaje y de «mimetismo táctico» como uno que trae a escena al «Yo teatral» (Urban, 1989). Urban estableció la diferencia esencial entre, de un lado el Yo del discurso donde el hablante se expresa como completamente inmerso en la voz de un personaje y, del otro, el Yo que juega el rol del personaje en cuestión sin que el discurso se elabore como una fusión de identidades. Al primero lo llama el Yo proyectivo y al segundo el Yo teatra/15. Suzanne Oakdale se interesa en la posición intermediaria entre ambos Yo discursivos (2005; 2007; 2009), precisamente la que corresponde con la de mimetismo táctico y empático (Busband \& Willesrslev, 2014: 16). Aquella que puede acarrear diversas y simultáneas identificaciones entre el Yo de todos los días y aquel de la narración, y que puede así permitir la «rotación» o circulación de las experiencias y perspectivas (Oakdale, 2009: 156; Basso, 1995). Lo que sucede en el relato de Erenando parece acomodarse bien a esta disposición que Oakdale encuentra se adapta mejor, en términos empíricos, a los «textos rituales» Kayabi. La salvedad que resuena es que la narración de mitos entre los matsigenkas no es un fenómeno de enunciación ritual, como tampoco la narración de Erenando pertenece completamente a la categoría del mito, al que los matsigenkas llaman kienkitsairintsi. El Yo discursivo de Erenando fluctúa entre el del punto de vista de los míticos ancestros y su propio punto de vista; pero al mismo tiempo esta fluctuación sirve para dar un paso adelante hacia la alteridad caníbal y ulteriormente retornar un paso atrás a reconstituir su propia identidad no salvaje. Erenando no avanza en su sed de desacuerdo perspectivista o curiosidad epistemológica a la manera de los ancestros, quienes parecen bastante menos propensos que él a incorporar la alteridad salvaje. Precipitando el desenlace lógico, el canibalismo, y aplicando el «mimetismo táctico», Erenando busca generar dos efectos complementarios: incorporar el prestigio que los matsigenkas atribuyen a los grandes viajeros de la identidad-alteridad, y confirmar la existencia de un colectivo de salvajes más salvajes que el colectivo que él representa.

La decitación de Erenando va más allá de la narración de su experiencia río arriba. La mitología matsigenka abunda en ejemplos de la paulatina incorporación de la alteridad o establecimiento de una «comunidad de substancia» por vías de la comensalidad (Arias, 2003: 78, 81; Renard-Casevitz, 1991; Rosengren, 2006b; Seeger et al., 1979: 11). Si al confrontarnos al escenario de la violencia, Erenando nos aportaba — para subrayar el relato - la prueba física de la cicatriz en su pierna, para el escenario de la comensalidad interpondrá la ingurgitación de un platillo propio de un devenir antropófago como los del mito. En una excursión de caza, mientras otros nos ocupábamos en cazar las presas que escapan a los tabúes alimenticios matsigenkas, Erenando, por toda prueba,

15 (...) the "I" discourse is not only an actual in-the-world subject, indexically referred to by means of the first person form. The discourse "I" can also be any being or entity, imaginary or not, capable of being raported as a speaker. The central question here concerns the relationship between this reported "I" and the indexical referencial "I" that points to a subject (Urban, 1989: 29). 
captura tres murciélagos —aunque insectívoros - que una vez en la aldea cocina él mismo en brocheta sobre el fuego. Su solitario festín estaba enteramente constituido de murciélagos como los de la segunda etapa de su Viaje y la escena, a media luz, azuzaba las risotadas de los hombres lejanamente cómplices y los cuchicheos, apenas obstaculizados por mi curiosidad, de las mujeres. El recurso extralingüístico de los murciélagos es la prueba práctica de una comensalidad aberrante. Sin más discurso que medie Erenando provoca la aberración de su entorno para suscitar la imagen de una comensalidad que lo ha en cierta forma transformado sin perderse en el otro. Sobre una base común de conocimiento mítico y de presunciones respecto a la naturaleza salvaje de quienes «hacen sin razón», el líder logra lo inusitado, actualizar en su cuerpo la presencia de un otro extremo escondido en las cabeceras.

\section{LECCIÓN DE LECTURA, UNA EXTRAÑA HOMOFONÍA}

La nota de campo más arriba se cierra con el acto de lectura de Erenando. Asistimos con tal acto a una intención cosmopolítica que difiere de la del célebre pasaje de Tristes Tropiques. En aquella lección de escritura el jefe de una banda nambikwara hace uso del aparato de «explotación» de la escritura sin dominar él mismo la producción de sentido escrito. Sobre un papel diseña turbulentas líneas horizontales a la manera del antropólogo. Su público es la banda analfabeta. En la lección de lectura kirineri, el jefe se aproxima a un calendario, señala los caracteres con el dedo, de izquierda a derecha, y enuncia lo que ha leído. Su público es un etnógrafo y tres matsigenkas, todos hábiles y ávidos lectores. Si bien el acto de Erenando se inscribe en el repertorio de una lección política, mi lectura del episodio difiere de la de Lévi-Strauss, primero por supuesto por el hecho de tratarse de un acto de «lectura» y no de «escritura», pero más importante aún por tratarse de un acto efectuado en el seno de una Comunidad Nativa16, es decir, un contexto «letrado», geopolíticamente estable y no una banda indígena analfabeta. El jefe kirineri parece inferir que en la configuración «civilizada» de la Comunidad Nativa la tecnología de la escritura ha jugado un papel constituyente. Pero infiere así mismo que este rol implica la comunicación personal con una entidad imperceptible. Si la comunicación normal requiere percibir y ser percibido (Hanks, 2000: 25; Taylor, 1993), la comunidad de intenciones con el colectivo de los blancos —y los matsigenkas-, que hacen uso de un medio de comunicación silencioso y ciego, ha de ser asunto extraordinario.

Este detalle técnico y a su vez epistemológico nos obliga a revisitar «la hipótesis marxista» de la Leçon. Es decir, reconsiderar la injerencia política de la escritura a la luz de la curiosidad epistemológica de un jefe indígena. Peter Gow llamaba ya la atención sobre un texto publicado por el Instituto Lingüístico de Verano. El

16 Nos encontrábamos en la C.N. de Nueva Luz. Las comunidades de influencia protestante en el Bajo Urubamba, Nueva Luz y Nuevo Mundo, creadas a finales de la década de los años 1960, se convertirán paulatinamente en enclaves esenciales de la administración misionera evangélica, de la administración de la labor escolar y de toda suerte de empresa económica. 
texto presentaba a un piro letrado narrando las sesiones de lectura de su primo mayor, el chamán Sangama, primer piro que «intentara»leer. La perspectiva histórica que aplica Gow permite resaltar una diferencia técnica y epistemológica en circunstancias de ebullición política. Sangama se comunicaba, «leyendo» textos, con entidades invisibles que le permitían observar el futuro, desplazar su visión a grandes distancias, en fin, facultades propias a la visión chamánica. Ello sucedía a comienzos del siglo XX. Su primo menor, el narrador, testigo de estas proezas, narra la historia a finales de los años 1940 siendo él mismo ya un profesor bilingüe alfabetizado. Entre ambas fechas, como lo hemos visto a propósito de los kirineri, los indígenas del Bajo Urubamba vivían bajo el yugo de la esclavitud local (Gow, 1996).

Pierre Déléage, restituyendo el texto sobre Sangama, indaga, desde una perspectiva comparativa con otros usos rituales en la Amazonía, las relaciones entre grafía, visión, libro y escritura. El autor subraya la importancia de las fuentes de autoridad sobrenaturales que, entre rituales chamánicos y ceremonias proféticas, permiten la difusión de un saber y de su epistemología, así como la asunción de una fuerza carismática entre los detentores de la escritura (Déléage, 2010). El libro, en ese contexto de transmisión prolijamente oral, no es sino un «vector de poder» en cuya capacidad de poner en contacto reposa la autoridad sobrenatural o chamánica del lector. Probablemente en los años treinta del siglo pasado, más de treinta años antes de la difusión de la escritura en la región del Picha, la aventura profética de un nomatsigenka adepto del misionero adventista Stahl, introdujo ceremonias de lectura que tuvieron un efímero apogeo pero una importante marca ideológica. El profeta itinerante cantaba «leyendo» un grupo de hojas que portaba siempre consigo. Santavankori, uno de los chamanes matsigenkas más recordados hoy en día, juzgó el instrumento de comunicación del profeta como propiedad de Kamasantaro, un Dueño de enfermedades. Tal asociación hace eco a la saga mítica del Korakonani, ampliamente difundida entre los matsigenkas pero desconocida entre el subgrupo kirineri (cf. nota 6). En ese mito el abusivo emperador Korakonani intenta hacerse de la mujer de un poderoso y discreto chamán matsigenka. El déspota es finalmente vencido por la locura que le provoca en algunas versiones la lectura de un libro, en otras su imagen retenida en una fotografía. Tecnologías introducidas en el mito bien sea por un cura o un blanco. Tras la lectura del libro Korakonani será interiormente asediado por una voz extraña; tras la captura fotográfica, su imagen se desdibujará progresivamente del papel. Luego de sepultado, Korakonani se vuelve el origen de enfermedades que se desplazan como un mortal gas por los aires, como una invisible e inaudible actividad que desafía al chamanismo. Ambas fuentes de «locura» nos recuerdan una vez más una de las maneras de abducción del alma frente a una interioridad parlante o a una imagen escindidas. Pero también la subyacente relación entre los modos extranjeros de «re-presentación», el exceso de autoridad y la consecuente desestructuración de la persona. Como a la base se encuentra la misma concepción de la persona entre matsigenkas ribereños y kirineris, estos últimos, no habiendo desarrollado en su ideología del lenguaje la caída de Korakonani, articulan una epistemología chamánica de la lectura que es más bien latente entre los primeros (Renard-Casevitz, 1980). 
En el origen de este debate, para Lévi-Strauss el jefe de la banda nambikwara fingía escribir para apropiarse así del instrumento de dominación que intuía en esta abstrusa técnica de comunicación. Técnica que no sería sino la refinada materialización comunicacional de sistemas históricamente constituidos justificando la explotación. En suma, Lévi-Strauss imputa al jefe indígena una utilización sociológica y no intelectual de la escritura (Lévi-Strauss, 1955: 316). Derrida, en una también ya célebre crítica, detecta una serie de distorsiones producto del logocentrismo y del fonologismo del proyecto del antropólogo (Derrida, 1967). Ambas fuentes de distorsión en realidad confluyen en una metafísica del sujeto que verifica la presencia de la interioridad en la apariencia fonética del pensamiento, apariencia de la que la escritura — fonética- sería la transcripción y máscara. Ahora bien, como vemos del ejemplo profético matsigenka y del déspota Korakonani, para los matsigenkas las cosas suceden de manera no tan lejana del fonologismo «occidental»; la sola cosa que cambia y que produce un envés epistemológico —así como una efervescencia ontológica一, es que la verificación de la interioridad comienza ejemplarmente en el otro. Si como veíamos más arriba, entre los matsigenkas es posible desde ciertos imbricados géneros narrativos hacer circular las experiencias o perspectivas y verificar así la existencia de entidades «míticas» o «imaginarias», acá incidimos sobre el hecho de que es también necesario, para ser uno, saber cómo y qué son los otros, pero saberlo en uno mismo dándole sentido a sus acciones e intenciones. Una vez más la mímesis empática permite explorar una entidad imaginaria, para el caso, aural (Seeger, 2015). Si habitualmente nos confrontamos a la imitación de «imágenes» o a partir de imágenes, acá se trata más bien de la lectura como imitación a partir de «sonoridades»; tal suele suceder en el aprendizaje de cantos chamánicos marentakantsi (Arias, 2015). Lo que Erenando quiere lograr comprendiendo la lectura es constatar la interioridad de la que la escritura $-y$ no solamente el objeto libro- es vehículo. No obstante una voz escindida como la del libro constituye una amenaza para el lector. Es esta misma comprensión, este escuchar voces, la que indujo a la muerte de Korakonani.

Retomando, el reproche de Derrida se dirige a los pilares de una presunción metafísica en la que Lévi-Strauss argumenta las consecuencias políticas de la escritura. Ahora bien, dada la acuidad etnográfica que prolifera después de Tristes Tropiques y de De la Grammatologie, este mismo reproche nos concede un nuevo ángulo de entrada a fenómenos como el de la lectura de Erenando. ¿Qué representa la lectura? De manera genérica la lengua matsigenka designa el acto de comprensión con la raíz -kem-, por ejemplo —en la primera persona- bajo el término nokemake. Tal término significa al mismo tiempo «he escuchado» y «he comprendido». Si proseguimos en fineza, en el otro polo de la comunicación, el del emisor, la raíz -kant- del término ikantaka (cf. supra), abarca en su complejo campo semántico tanto la acción de hablar como la de pensar. Para ser más preciso, lo que parece suceder es que la raíz equipara ambas acciones en tanto que operaciones internas de «relación»; tanto en el sentido de referir como en el de poner en relación asunciones para de ellas erigir una representación. Este tipo de representación parece así establecerse como una «imagen acústica». 
A diferencia del término que sirve para designar el acto de pensar (isuretaka), que puede referir a toda suerte de proceso o acción mental, ikantaka, usado en ese mismo propósito, pone el acento en el inner speech. El término, en su uso lingüístico reflexivo nos coloca entonces primero que nada en el ámbito del acto mental de representación verbal sonora. Además de establecer la semejanza entre la voz y el pensamiento, el término se emplea de modo estativo, es decir para marcar la presencia o identidad. Veamos estos tres usos en un extracto mítico sobre las transformaciones de los árboles Kovanti y Avavo:

(...) imatikaiganakera ikanti: Kovanti Kovanti Kovanti ipigatake Kovanti. Kemisanatake irirori, iriro ikantakenkani: Kovanti yogari irapitene iriro okantakani Avavo (...) (Arias, 2003: 48)

(...) él cantaba diciendo: Kovanti Kovanti Kovanti intoxicado Kovanti. El otro comprendió y piensa: Kovanti es él y la que va con él es (parece) Avavo (... ${ }^{17}$.

En la teoría del espíritu matsigenka, la apariencia sonora del pensamiento — sin ser exclusivo dato- es medular en tanto que fenómeno constitutivo de la persona. Toda entidad animada está dotada de un lenguaje cuya característica fonoauditiva, no necesariamente comprensible, es denominada iriniane. Así el español en tanto que lengua es denominado iriniane virákocha, el chillido del murciélago iriniane pijiri y la «palabra de Dios» iriniane Tasorintsi. Los cazadores por ejemplo señalan a menudo que sus presas son «políglotas» y pueden comprender la lengua del cazador. Durante sus expediciones los cazadores utilizan perífrasis para ponerse de acuerdo sobre el tipo de emboscada a adoptar, pues de otra manera los animales podrían desbaratar el plan. El iriniane que poseen animales como humanos designa al lenguaje y a uno de los componentes relacionales que especifica la acción del isure (cf. nota 7). En una interacción - ya sea en los dos sentidos intencional o no- es el decisivo paso a la comprensión (nokemake) de la emisión sonora lo que será señalado mediante el término ikant- («él habla», «él piensa»). El término se asemeja a la expresión en español «es su parecer», solo que así traducido anexa también el sentido de «apariencia», denotando la idea de «parecer una persona», tal como lo expresa el término imatsigenkatira más arriba analizado (cf. nota 4). Es decir, como si la voz que emerge durante la lectura del libro prorrumpiera en la forma (humana) de la interioridad de una persona. El libro puede ser depositario de un inner speech si bien puede tan solo tratarse de una «percepción» transitoria en el complejo proceso de adquisición de la comunicación escrita.

Entre blanco, matsigenka y kirineri existe una implícita categorización respecto a la escritura, su marca histórica se deja apreciar en el desarrollo exclusivo de la caída de Korakonani entre los matsigenkas ribereños. Erenando es perfectamente consciente del hecho que los matsigenkas del gran río saben leer porque aprendieron de los blancos. Esta jerarquía y la consistencia del progreso que viene con él, son aliciente

17 Veamos de pasada que en el extracto el narrador emplea también la raíz $\mathbf{k e m}$ - (Kemisanatake) poniendo en evidencia la relación entre escuchar/comprender y la «representación» que se infiere del canto que entona el árbol Kovanti. 
de su curiosidad epistemológica. La lectoescritura como técnica «esotérica» entra en el rango de actividades que propician un buen vivir. En ninguna sociedad el aprendizaje de la escritura es un fenómeno ideológicamente neutro. No es difícil detectar el que en colectivos como el matsigenka, donde un buen porcentaje de la población se ha reagrupado en comunidades estructuradas en torno a escuelas, estas fundadas por profesores nativos formados por el Instituto Lingüístico de Verano, el rol de la escritura sea indisociable de una particular «comunidad imaginada». En el contexto histórico inmediatamente anterior de la creación de esas comunidades (los años cincuenta y sesenta del siglo XX, cf. supra; Davis, 2002), la escritura representaba el instrumento que potenciaría una transformación favorable de las condiciones de dominación y explotación. El cariz del cambio buscado en la era de la «buena nueva» escrita queda puesto de relieve por los hiperbólicos nombres de tres de las primeras comunidades formadas entonces: Nueva Vida, Nueva Luz y Nuevo Mundo. La burocracia comunitaria de hoy en día prorrumpe como una nueva fase de la compleja relación intelectual y sociológica con la escritura. Como veíamos más arriba, Erenando asistió durante algún tiempo, entre la década de 1970 y comienzos de la de 1980, a las escuelas de las Comunidades Nativas matsigenkas de Nueva Luz y Nueva Vida, sobre el gran río; tiempo en el que aprendió los rudimentos de la inscripción fonética. El líder kirineri se sitúa así un paso atrás del chamanismo «iletrado» de Sangama, y un paso adelante en las arenas del «carisma» político. Ambos rasgos muestran que la perspectiva chamánica puede ser compartida por otros que no sean especialistas, y que también el uso intelectual y no solamente sociológico de la lectura inviste de carisma.

En Erenando la impresión de la lectoescritura es aún solidaria del buen vivir que puede generar como técnica chamánica. Cuando Erenando, frente al calendario, siguiendo con el dedo cifra tras cifra de «2010», pronuncia «SUYO», nos demuestra de tal acto —sociológico e intelectual— que domina la misteriosa técnica de los blancos, es decir que - a diferencia del jefe nambikwara y del chamán Sangama - ha comprendido en suficiente medida el artilugio fono-auditivo que los grafemas movilizan. Pude comprobar más tarde que Erenando, dando un giro particular a los útiles mnemónicos de su propia tradición (Renard-Casevitz, 1980), retenía la correspondencia de algunos pocos grafemas y fonemas, siendo capaz así de resaltar algunas mínimas unidades de sentido en textos como la Biblia —en español-que un misionero le había obsequiado presentándola con la invitación al quiprocuo: iriniane Tasorintsi (La palabra del [dios] que soplando transforma). Es en ese sentido que las grafías del «libro» (sankevanti) — como las del jaguar (sankenari)_ actúan enunciando (ikantaka) y el lector entiende (ikemake) escuchando. Del «objeto» libro puede abducirse, en el sentido de Peirce, una interioridad puesto que produce «imágenes acústicas», es decir, como lo veíamos más arriba, tiene pasajeramente la apariencia de persona (imatsigenkatira). No es difícil ver —o escuchar- en 2010: SOIO; que yo transcribí, con corrección ortográfica y sin realmente comprender sus implicaciones, como «suyo». En el contexto «letrado» donde toma lugar esta lección de lectura, horas antes de partir a la región de los kirineri, la intención de Erenando se afirma clara: darse a oír como un competente usuario de una tecnología que, antes que como vacuo 
instrumento de sometimiento, parece interesarle por su capacidad de transformarlo empáticamente. Transformarlo dado que en él hace resonancia la voz silenciosa, íntima, del alter invisible, como lo preconiza el aprendizaje chamánico. Buscando una comunidad de intenciones, Erenando abduce lógicamente una interioridad de la intencionalidad (comunicativa) de un «objeto» sin exterioridad humana. En esta ocasión el acto de lectura, que es una disposición a escuchar según Erenando, no va dirigido a «hacer creer» a su colectivo que ha accedido al misterioso modo virákocha de comunicación con lo invisible. Antes bien es dar a «entender», con la anuencia de los «letrados», que puede escuchar al interlocutor invisible18.

\section{CONCLUSIONES}

Devenir caníbal e interlocutor de los invisibles no es un contrasentido. El cromatismo ontológico que de ese modo se procura el jefe kirineri es la realización de una particular estructura estructurante: es él mismo siendo otros. Erenando adquiere mediante la mímesis empática los atributos de sus hipotéticos canibal y blanco. La comensalidad media su devenir «salvaje» y la comprensión el de devenir «Civilizado». La paradójica simplicidad de «ser uno mismo siendo otros» implica imaginar por una parte una particular estructura de la persona, enseguida una forma social que la contiene y produce y, más allá de sus fronteras, una alteridad que podría completarlas. Persona y colectivo, proyectados hacia fuera, requieren de medios de integrar la alteridad. La decitación y la lectura han constituido para Erenando los artefactos mentales con los que ha evidenciado su relación con el otro en la construcción del sí mismo. Así Erenando transmite la experiencia de mimetismo a un «público» que no necesariamente coincide solamente con su colectivo originario, sino que, en el de la coyuntura del contacto, con aquellos que encarnan diferentes grados de alteridad.

Si los medios de integración del alter han sido la «comensalidad» y la «comprensión», ambos solo pueden ser entendidos como medios de transformación dentro de una lógica de producción de la persona en circunstancias históricas particulares de contacto. La significación social de la «comprensión», por ejemplo, puede ser entendida desde el rol de la lectoescritura en el progreso regional; o bien en la «domesticación del pensamiento salvaje»; o, como lo veíamos a propósito de Lévi-Strauss, como la imposición de una estructura intelectual de dominación social; sin embargo, visto también desde la postura matsigenka, la de su particular apertura fono-auditiva al otro, la transformación a través de la lectura nos presenta otros retos epistemológicos. A saber, el rol que ontologías amerindias otorgan a epistemologías extranjeras en el ordenamiento de su propio mundo, social e intelectual, físico y espiritual, visual y aural.

18 Aunque misteriosa y medianamente visible, puesto que Erenando señala (en español) que ve el «pelo» (los días del mes de julio), tal como Sangama veía los labios rojos de su interlocutor en el papel. 
Asimismo, la figura del salvaje solamente puede ser entendida circunscribiéndola a su contexto histórico de emergencia. La genealogía del término kirineri muestra que en sus intermitentes apariciones, esa figura puede llevar inscritas formas antinómicas de representarla. Sus formas paradigmáticas son el salvaje «alevoso» según los blancos, y el salvaje «que hace sin arreglo a un plan»o «de quien es imposible elucidar las intenciones» (kogapage) según los matsigenkas. En ambas representaciones se delata la mirada de dos grados diferentes de alteridad en el curso de la convulsa historia colonial y republicana del Perú. Con ellos se ponen de relieve también dos maneras de comprender la estructura de la persona, las posibilidades de su injerencia en la realidad social y las estrategias miméticas en práctica. Ambas estructuras de la persona coinciden sin embargo en un mismo sustrato de sociabilidad que les da consistencia, la intencionalidad. A través de ella se puntúa el interés, latente en toda psicología folk, por la relación entre la producción de la persona y el ethos de una sociedad. En el marco del «progreso», aparatos políticos regionales y económicos mundiales pulsaban distinciones «operativas» en los que la violenta «alevosía» del kirineri se conjugaba bien a una intencionalidad contra la meta republicana. En cambio, la postura matsigenka (ribereña) sitúa la violencia kirineri no como el medio por el cual un fin será alcanzado, sino como el signo de la ausencia de todo fin, o de una comunidad de intenciones suficientemente opaca y reactiva al «ensanchamiento».

No obstante, mediante una táctica utilización de la facultad mimética, Erenando consigue, encarnándolo, hacer aparecer al verdadero salvaje, el antropófago kirineri-kogapakori. Del mismo modo, escuchando el inner speech de una entidad invisible, el líder kirineri logra hacer de la comprensión un medio de transformación. Desde su posición ha implicado mediante herramientas intelectuales y mecanismos sociológicos el progresivo ensanchamiento de su colectivo en las difíciles circunstancias actuales de contacto. Los espectros del salvaje y de la entidad invisible repercuten sobre las fronteras mismas de la topografía moral e idioma de la alteridad, empujándolas a concebir de común acuerdo nuevas figuras de alteridad. En resumidas cuentas los salvajes que emergen de la experiencia de Erenando son más salvajes porque sin arreglo al fin de construirse en la apertura al otro, devienen no caníbales que integran otros sujetos sino más bien antropófagos que perennizan su solipsismo. Por su parte, la entidad invisible que se deja escuchar en la escritura representa para Erenando una modalidad de buen vivir a la imagen de los colectivos matsigenka del gran río.

\section{Agradecimientos}

En total son veintidós meses de trabajo de campo los que he realizado en diversas cuencas del territorio matsigenka. Los cinco meses de trabajo de campo (entre 2009 y 2010) que nutren este ensayo fueron posibles gracias a un fondo de misión científica del CNRS y a dos becas de campo, una del Legs Lelong y otra del EHESS. Agradezco a las federaciones Matsigenka Ceconama y Comaru por su gentil apoyo, como también a los matsigenkas del río Pakiría. Asimismo a las comunidades de Nueva Luz y Nuevo Mundo, especialmente a Efraín Seferino, Luis Vásquez y Sarova. Este trabajo se enriqueció de las observaciones de 
Magda Dziubinska, Javier García Liendo y de los evaluadores anónimos del BIFEA; a ellos mi gratitud. Toda interpretación contenida en el presente texto es de mi responsabilidad.

\section{Referencias citadas}

ARIAS, E., 2001 - Noches, cosmos. Claroscuros entre los matsigenka. Anthropologica, 19: 147-170.

ARIAS, E., 2003 - Mitología de los Matsigenka que pueblan el Río Picha: Igenkitsaneegi matsigenka timaigatsirira anta pichaku, 102 pp.; Lima: Termil.

ARIAS, E., 2015 - Las turbulencias del lenguaje: mímesis inter-específica y autodiferenciación en los cantos rituales matsigenka. In: Sudamérica y sus mundos audibles: Cosmologías y prácticas sonoras de los pueblos indígenas (B. Brabec de Mori, M. Lewy \& M. A. García, eds.): 47-61; Berlín: Ibero-Amerikanisches Institut - Preussischer Kulturbesitz.

BAER, G., 1994 - Cosmología y shamanismo de los Matsiguenga (Perú Oriental), 400 pp.; Quito: Abya-Yala.

BASSO, E., 1995 - The last cannibals: A South American oral history, 319 pp; Austin: University of Texas press.

BEIER, C. \& MICHAEL, L., 1998 - Un Informe sobre los nanti del Camisea, desde el punto de vista de los factores que afectan su bienestar y autonomía (http://www.cabeceras. org/Nantilnforme1.pdf)

BUBANDT, N. \& WILLERSLEV, R., 2015 - The Dark Side of Empathy: Mimesis, Deception, and the Magic of Alterity. Comparative Studies in Society and History, 57 (1): 5-34.

CLASTRES, P., 1974 - La société contre l'État : recherches d'anthropologie politique, 186 pp.; París: Les Éditions de Minuit.

COURSE, M. \& OAKDALE, S., 2014 - Introduction. In: Fluent selves: autobiography, person, and history in lowland South America (S. Oakdale \& M. Course, eds.): 1-32; Lincoln: University of Nebraska press.

DAVIS, P., 2002 - Los machiguengas aprenden a leer: Breve historia de la educación bilingue y el desarrollo communal entre los machiguengas del Bajo Urubamba, 131 pp.; Lima: Pontificia Universidad Católica del Perú, Instituto Lingüístico de Verano.

DÉLÉAGE, P., 2009 - Le chant de l'anaconda. L'apprentissage du chamanisme chez les Sharanahua (Amazonie occidentale), 409 pp.; Nanterre: Société d'ethnologie, coll. « Recherches américaines » 8.

DÉLÉAGE, P., 2010 - Rituels du livre en Amazonie. Cahiers des Amériques Latines, 63-64: 229-250.

DELEUZE, G., 1985 - L'image-temps, 378 pp.; París: Édition de Minuit.

DENNETT, D., 1987 - The Intentional Stance. 388 pp.; Cambridge, Massachusetts: The MIT press.

DERRIDA, J., 1967 - De la Grammatologie, 448 pp.; París: Les Éditions de Minuit.

DESCOLA, P., 2005 - Par-delà nature et culture, 623 pp.; París: Gallimard.

DURANTI, A., 2006 - The Social Ontology of Intentions. Discourse Studies, 8 (1): 31-40.

DURANTI, A., 2015 - The anthropology of intentions: language in a world of others, 297 pp.; Cambridge: Cambridge University Press.

ERIKSON, P., 1986 - Altérité, tatouage, et anthropophagie chez les Pano : la belliqueuse quête du soi. Journal de la Société des Américanistes de Paris, 72: 185-210. 
El jefe deviene un lector caníbal: mímesis, persona e intención entre los matsigenkas

FAUSTO, C., 2002 - Banquete de gente: Comensalidade e Canibalismo na Amazônia. Mana, 8 (2): 7-44.

FAUSTO, C., 2007 - Feasting on People: Eating Animals and Humans in Amazonia. Current Anthropology, 48 (4): 497-530.

FERRERO, A., 1947 - Rutas del Urubamba. Con las tribus indígenas. Revista Misiones Dominicas, 163: 208-218.

FERRERO, A., 1967 - Los Machiguengas: Tribu selvática del Sur - Oriente Peruano, 441 pp.; Puerto Maldonado: Instituto de Estudios Tropicales «Pio Aza».

FRANCHETTO, B., 2008 - A guerra dos alfabetos: Os povos indígenas na fronteira entre o oral e o escrito. Mana, 14 (11): 31-59.

GOW, P., 1991 - Of Mixed Blood, Kinship and History in Peruvian Amazonia, 307 pp.; Oxford: Clarendon Press.

GOW, P., 1996 - ¿Podía leer Sangama? Sistemas gráficos, lenguaje y shamanismo entre los Piro (Perú Oriental). In: Globalización y cambio en la Amazonia indígena (F. Santos Granero, ed.): 261-287; Quito: Facultad Latinoamericana de Ciencias Sociales, Abya Yala.

GOW, P., 2001 - An amazonian myth and its history, 360 pp.; Oxford: Oxford University Press.

GOW, P., 2011 - "Me deixa em paz!" Um relato etnográfico preliminar sobre o isolamento voluntário dos Mashco. Revista de Antropologia, São Paulo, USP, 54 (1): 11-46.

GOW, P., 2014 - "This Happened to Me": Exemplary Personal Experience Narratives among the Piro (Yine) People of Peruvian Amazonia. In: Fluent selves: autobiography, person, and history in lowland South America (S. Oakdale \& M. Course, eds.): 6991; Lincoln: University of Nebraska press.

GRAY, A., 2002 - Los Arakmbut: mitología, espiritualidad e historia, 395 pp.; Lima: Grupo de Trabajo Internacional sobre Asuntos Indígenas (IWGIA).

HANKS, W., 2000 - Intertexts: Writings on Language, Utterance, and Context, 325 pp.; Lanham, Md.: Roman \& Littlefield Publishers, Inc.

JOHNSON, A., 2003 - Families of the forest: The Matsigenka indians of the Peruvian Amazon, 258 pp.; Berkeley (Calif.): University of California press.

LELONG, B., 1974 - La Rivière du maïs, 224 pp.; París: J.-C. Lattès.

LEVI-STRAUSS, C., 1955 - Tristes Tropiques, 464 pp.; París: Plon.

LEVI-STRAUSS, C., 1991 - Histoire de lynx, 358 pp.; París: Plon.

LEVI-STRAUSS, C. \& ERIBON, D., 1988 - De près et de loin, 254 pp.; París: Odile Jacob.

LIMA, S. T., 2005 - Um peixe olhou para mim: o povo Yudjá e a perspectiva, 399 pp.; Sao Paulo: Universidade Estadual Paulista

MARCOY, P., 1869 - Voyage à travers L'Amérique du Sud: De l'Océan Pacifique à l'Océan Atlantique, 2 volumes; París: Libraire de L. Hachette et C.

MERLEAU-PONTY, M., 1964 - Le visible et l'invisible, 359 pp.; París: Gallimard.

MICHAEL, L., 2015 - The cultural bases of linguistic form: The development of Nanti quotative evidentials. In: Language and Environment: social, cultural and natural factors (R. De Busser \& R. J. LaPolla, eds.): 99-133; Amsterdam, Philadelphia: John Benjamins.

MICHAEL, L. \& BEIER, C., 2004 - Una Breve Historia del Pueblo Nanti hasta el año 2004 (http://www.cabeceras.org/cabeceras_nanti_histor_2004.pdf) 
OAKDALE, S., 2005 - "I Foresee my Life": The Ritual Performance of Autobiography in an Amazonian Community, 206 pp.; Lincoln: University of Nebraska Press.

OAKDALE, S., 2007 - Anchoring "The Symbolic Economy of Alterity" with Autobiography. Tipití: Journal of The Society for the Anthropology of Lowland South America, Vol. 5 (1): 51-78.

OAKDALE, S., 2009 - Ritual and the Circulation of Experience. In: Ritual Communication (E. Basso \& G. Senft, eds.): 153-170; Nueva York: Berg.

RENARD-CASEVITZ, F.-M., 1980 - Inscriptions. Un aspect du symbolisme matsiguenga. Journal de la Société des Américanistes, vol. 67 (1): 261-295.

RENARD-CASEVITZ, F.-M., 1985 - Guerre, Violence et Identité à partir de Sociétés de piémont amazonien des Andes centrales. Cahiers ORSTOM, série Sciences Humaines, XXI (1): 81-98.

RENARD-CASEVITZ, F.-M., 1991 - Le banquet masqué: une mythologie de l'étranger, 280 pp.; París: Lierre \& Coudrier.

RENARD-CASEVITZ, F.-M., 1995 - Les Hommes vêtus : travaux sur l'ensemble Campa de I'Amazonie péruvienne à partir de sa composante Matsiguenga, 728 pp.; s.n.

RENARD-CASEVITZ, F.-M., 1999 - Ideología Matsiguenga: entre lo local y lo global. Anthropologica, 17: 21-62.

ROSENGREN, D., 1987 - In the eyes of the beholder: leadership and the social construction of power and dominance among the Matsigenka of the Peruvian Amazon, 231 pp.; Göteborg: Göteborg etnografiska museum.

ROSENGREN, D., 2000 - The aesthetics of conviviality in the Amazon. In: The antropology of love and anger (Overing \& Pases, eds.): 221-234; Londres: Routledge.

ROSENGREN, D., 2004 - Los Matsigenka. In: Guía Etnográfica de la Alta Amazonía, Volumen 4 (F. Santos Granero \& F. Barclay, eds.): 1-158; Lima: Smithsonian Tropical Research Institute, Instituto Francés de Estudios Andinos (IFEA).

ROSENGREN, D., 2006a - Transdimensional relations: on human-spirit interaction in the Amazon. Journal of the Royal Anthropological Institute (N.S.), 12: 803-816.

ROSENGREN, D., 2006b - Matsigenka Corporeality, a Nonbiological Reality: On Notions of Consciousness and the Constitution of Identity. Tipiti: Journal of The Society for the Anthropology of Lowland South America, 4 (1\&2): 81-102.

ROSENGREN, D., 2015 - Being and Becoming: On Conditions of Existence in the Amazon. Tipiti: Journal of The Society for the Anthropology of Lowland South America, 13 (1): 80-94.

SALA, N., 1998 - Cusco y su proyección en el Oriente amazónico, 1800-1929. In: Fronteras, colonización y mano de obra indígena en la Amazonía andina, siglos XIXXX (P. García Jordán, ed.): 402-528; Lima: Pontificia Universidad Católica del Perú (PUCP), Universitat de Barcelona.

SANTOS-GRANERO, F., 2007 - Time is disease, suffering, and oblivion: Yanesha historicity and the struggle against temporality. In: Time and memory in indigenous Amazonia: Anthropological perspectives (C. Fausto \& M. Heckenberger): 47-73; Gainesville: University Press of Florida.

SEEGER, A., DA MATTA, R. \& VIVEIROS DE CASTRO, E., 1979 - A Construçao da Pessoa nas Sociedades Indígenas Brasileiras. Boletim do Museu Nacional, Rio de Janeiro, 32: 2-19.

SEEGER, A., 2015 - El oído etnográfico. In: Sudamérica y sus mundos audibles: Cosmologías y prácticas sonoras de los pueblos indígenas (B. Brabec de Mori, M. Lewy \& M. A. García, eds.): 27-36; Berlín: Ibero-Amerikanisches Institut-Preussischer Kulturbesitz. 
SEVERI, C., 2009 - L'univers des arts de la mémoire. Anthropologie d'un artefact mental. Annales. Histoire, Sciences Sociales, 64e, n. 2: 463-493.

SHEPARD, G., 1999 - Pharmacognosy and the Senses in Two Amazonian Societies; Berkeley: University of California. Tesis de doctorado, Medical Anthropology Program.

SHEPARD, G., 2002 - Three days for weeping: dreams, emotions, and death in the Peruvian Amazon. Medical Anthropology Quartely, 16 (2): 200-229.

SURRALLES, A., 2003 - Au cœur du sens : perception, affectivité, action chez les Candoshi, 278 pp.; París: CNRS éd., Éd. de la Maison des sciences de l'homme.

SWIERK, K., 2003 - Informe sobre el estudio de reconocimiento realizado entre los nativos Matsigenka recién contactados, Río Paquiría.

(http://www.cabeceras.org/paquiria_2002.2.pdf)

SWIERK, K., 2006 - El Territorio de los Matsigenkas Paquirianos. (http://www.cabeceras.org/swierk_2004.htm)

TAUSSIG, M., 1993 - Mimesis and alterity: a particular history of the senses, 299 pp.; Nueva York: Routledge.

TAYLOR, A.-C., 1993 - Des Fantômes stupéfiants. Langage et croyance dans la pensée achuar. L'Homme, 33 (2-4): 429-447.

TOMASELLO, M., 2014 - A natural history of human thinking, 178 pp.; Cambridge (Mass.): Harvard University Press.

TRIPP, R., 1995 - Diccionario Amarakaeri - Castellano, 359 pp.; Pucallpa: Ministerio de Educación, Instituto Lingüístico de Verano.

URBAN, G., 1989 - The "I" of discourse. In: Semiotics, self and society (B. Lee \& G. Urban, eds.): 27-51; Berlín, Nueva York, Amsterdam: Mouton de Gruyter.

VILAÇA, A., 2005 - Chronically unstable bodies: Reflections on Amazonian corporalities. Journal of the Royal Anthropological Institute (N.S.), 11 (3): 445-64.

VILAÇA, A., 2015 - Dividualism and individualism in indigenous Christianity, a debate see from Amazonia. HAU: Journal of Ethnographic Theory, 5 (1): 197-255.

VIVEIROS DE CASTRO, E., 2009 - Métaphysiques cannibales, 206 pp.; París: Presses Universitaires de France.

VON BRUCK, G. \& BODENHORN, B., 2006 - The Anthropology of Names and Naming, 290 pp.; Nueva York: Cambridge University Press. 